\title{
Interannual Variability of Tropical Rainfall Characteristics and the Impact of the Altitude Boost from TRMM PR 3A25 Data
}

\author{
Tetsuo NAKAZAWA \\ Meteorological Research Institute, Japan Meteorological Agency, Tsukuba, Japan \\ and \\ Kavirajan RAJENDRAN \\ CSIR-Centre for Mathematical Modelling \& Computer Simulation, \\ National Aerospace Laboratories, Bangalore, India \\ (Manuscript received 29 June 2008, in final form 8 January 2009)
}

\begin{abstract}
Global and regional interannual variations of rainfall characteristics over the tropics were examined by applying empirical orthogonal function (EOF) analysis to TRMM PR 3A25 data from December 1997 to December 2007. The TRMM PR 3A25 data and other TRMM datasets detect the interannual variation of rainfall over the tropics, in concert with the SST change, which is closely related to the El Niño/La Niña cycle, including the pseudo-El Niño periods in 2002 and 2004. In addition, we examined the impact of the altitude boost of the TRMM satellite from $350 \mathrm{~km}$ to $400 \mathrm{~km}$ in August 2001 and found that the boost affects the annual cycle in light rain rates (total, convective, and stratiform). A baseline shift occurs in the annual cycle of light convective rain rate (convRainH) with more (less) frequent occurrence before (after) the boost.

In addition, amplitude changes were observed in the annual cycle of light stratiform and total rain rates with more (less) frequent occurrence before (after) the boost. However, for the interannual variation, the coherent spatio-temporal structure of the El Niño/La Niña cycle is evident, and the interannual variation does not indicate any boost impact. In contrast, for heavy convRainH, the number events decreases after the boost, especially over land; however, it is difficult to conclude that this reduction is related to the boost.
\end{abstract}

\section{Introduction}

The Tropical Rainfall Measuring Mission (TRMM) satellite was launched in November 1997 to measure precipitation over the tropical area $\left(37^{\circ} \mathrm{N}\right.$ to $\left.37^{\circ} \mathrm{S}\right)$ with the use of several sensors. The Precipitation Radar (PR), developed in Japan, is a key sensor used to provide vertical profiles of rain over the tropical land and ocean areas.

Corresponding author: Tetsuo Nakazawa, Meteorological Research Institute, Japan Meteorological Agency, 1-1 Nagamine, Tsukuba, Ibaraki 305-0052, Japan E-mail: nakazawa@mri-jma.go.jp

(2009, Meteorological Society of Japan
In August 2001, the TRMM satellite was boosted up from $350 \mathrm{~km}$ to $400 \mathrm{~km}$ in altitude to extend its life. As the PR is an active sensor, it was expected that sensitivity would be degraded due to the boost. Hence, to clearly understand the interannual variation, it is necessary to examine the impact of the boost. Several studies have analyzed this impact. DeMoss and Bowman (2007) studied the changes in TRMM rainfall data due to the boost, using rain gauges of the National Oceanic and Atmospheric Administration (NOAA) tropical ocean buoys, and found that for the TRMM Microwave Imager (TMI), the bias is $12 \%$ lower than the gauges before the boost and $1 \%$ lower after the boost. In addition, for TRMM PR, the bias was significantly lower during both periods, but 
the change in bias was not statistically significant. Shin and Chiu (2008) examined the boost effects on oceanic rainfall estimates in the TRMM TMI 3A11 algorithm and found that the global rainfall in the TMI algorithm increases by $0.17 \mathrm{~mm}$ per day, or $6.5 \%$, after the boost. This result is consistent with the findings of DeMoss and Bowman (2007). However, few studies have described changes in rain characteristics due to the altitude boost. In addition, the timing of the boost coincides with the period of the phase shift from the La Niña to El Niño. Thus, it is important to separate the impact of the boost from that of the El Niño-Southern Oscillation (ENSO) cycle.

With these objectives, we analyzed the TRMM PR 3A25 dataset, which includes not only the monthly mean rain rate, but also many statistical values (e.g., monthly histograms of rain rates (total, convective, and stratiform) and storm height) in each $5^{\circ}$ longitude/latitude box over the global tropics.

\section{Data}

The TRMM PR 3A25 version 6 dataset (Iguchi et al. 2000) provides various monthly statistics of rain characteristics from the level-2 TRMM PR products from December 1997 to date. For example, the dataset contains mean, standard deviations and count values, histograms, correlation coefficients, and $\mathrm{R}-\mathrm{Z}$ coefficients $\mathrm{a}$ and $\mathrm{b}$ for $\mathrm{R}=\mathrm{AZ}$.

The 3A25 dataset is available in two horizontal resolutions of $0.5^{\circ} \times 0.5^{\circ}$ and $5^{\circ} \times 5^{\circ}$ grids. In this study, we used only the $5^{\circ} \times 5^{\circ}$ gridded product. Also, the rainfall data used in this study is rain at $2 \mathrm{~km}$ (RainH at $2 \mathrm{~km}$ ); we did not use the near-surface rain rate (surfRainH) or the estimated surface rain rate (e_surfRainH) because these surface rain data may have suffered from cluttering or vertical interpolation error.

In addition to the TRMM PR 3A25 dataset, we used the outgoing long wave radiation (OLR) dataset (Liebmann and Smith 1996) for the concurrent period obtained from the NOAA Climate Data Center (NOAA Interpolated daily OLR), which is available at http://www.cdc.noaa.gov/cdc/data.interp_OLR.html. We also used the sea-surface temperature (SST) dataset obtained from the NOAA Climate Data Center (Optimum Interpolated SST, (OISST)) (Reynolds et al. 2002), which is available at http:// www.cdc.noaa.gov/cdc/data.noaa.oisst.v2.html.

\section{Results}

3.1 From La Niña to El Niño
The OLR data is usually used as a proxy for convective activity over the tropical and sub-tropical regions. Lower (higher) OLR values may represent active (inactive) convective activity, due to the deeper (shallower) convection with colder (warmer) cloud top temperature. Figure 1a depicts the temporal change of OLR during the TRMM flying period. Before the boost ((BB) from August 1998 to July 2001), OLR less than $220 \mathrm{~W} \mathrm{~m}^{-2}$ is dominant over the maritime continent, equatorial Africa, and South America. After the boost ((AB), from September 2001 to August 2007, in the middle of Fig. 1a), OLR over the maritime continent is higher (i.e., the convective activity is weaker), and it becomes lower over the equatorial west-central Pacific. This is due mainly to the prevalence of the canonical El Niño or pseudo-El Niño (Ashok et al. 2007) phases. The Japan Meteorological Agency (JMA) defines the El Niño and La Niña seasons, based on the six-month successive SST warmer anomalies greater than $0.5^{\circ} \mathrm{C}$ over the Niño-3 $\left(5^{\circ} \mathrm{N}\right.$ to $5^{\circ} \mathrm{S}, 150^{\circ} \mathrm{W}$ to $\left.90^{\circ} \mathrm{W}\right)$ region. These seasons after the TRMM launch are listed in Table 1. As per the JMA definition of the El Niño/La Niña season, an El Niño season occurred from the boreal summer of 2002 to the winter of 2002/2003. Ashok et al. (2007) identified this period as the strong pseudo-El Niño period. Another pseudo-El Niño period occurred in 2004. Ashok et al. (2007) identified two different dominant patterns of oceanatmospheric coupled modes over the Pacific: the canonical El Niño mode and the pseudo-El Niño mode. The canonical El Niño mode is characterized by anomalous warm SST over the equatorial eastern Pacific, whereas the pseudo-El Niño mode is characterized by warmer SST over the equatorial central Pacific. The difference (AB-BB) reveals the ENSO signal as a sea-saw pattern between the maritime continent and the central Pacific. Positive (negative) OLR anomalies over the maritime continent (central Pacific) indicate that the convective activity is

Table 1. El Niño and La Niña seasons based on the Japan Meteorological Agency (JMA) definitions of the seasons, based on the six-month successive SST warmer anomalies greater than $0.5^{\circ} \mathrm{C}$ over the Niño-3 region $\left(5^{\circ} \mathrm{N}\right.$ to $5^{\circ} \mathrm{S}, 150^{\circ} \mathrm{W}$ to $\left.90^{\circ} \mathrm{W}\right)$.

\begin{tabular}{ll}
\hline \multirow{2}{*}{ El Niño Season } & Spring 1997 - Spring 1998 \\
& Summer 2002 - Winter 2002/2003 \\
\hline \multirow{3}{*}{ La Niña Season } & Summer 1998 - Spring 2000 \\
& Autumn 2005 - Spring 2006 \\
& Spring 2007 - Spring 2008 \\
\hline
\end{tabular}



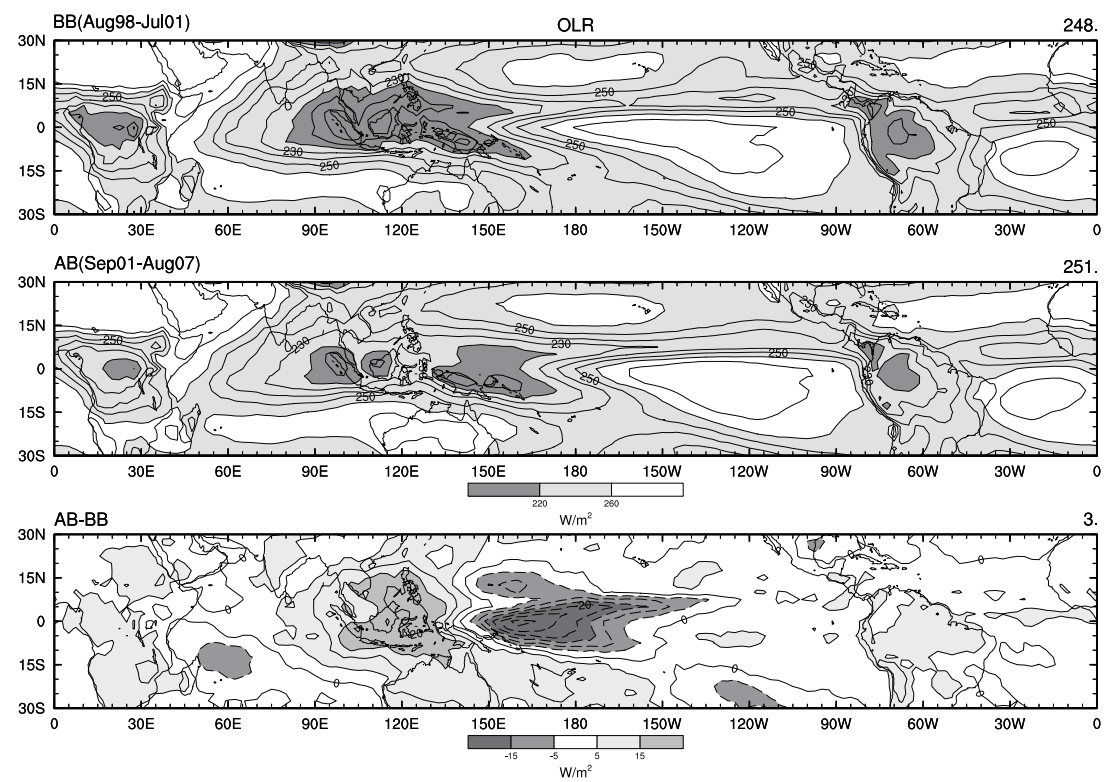

Fig. 1a. Mean OLR (unit: $\mathrm{W} \mathrm{m}^{-2}$ ) before the boost (BB), averaged between August 1998 and July 2001; after the boost (AB), averaged between September 2001 and August 2007; and the difference between them (AB-BB). For BB and AB, dark (light) shading denotes areas of active convection below 220 (260) units with intervals of 10 units. For the AB-BB, the negative dark shaded areas are dashed-lined with intervals of 5 units. The number at the right top in each figure denotes the global mean of the OLR.

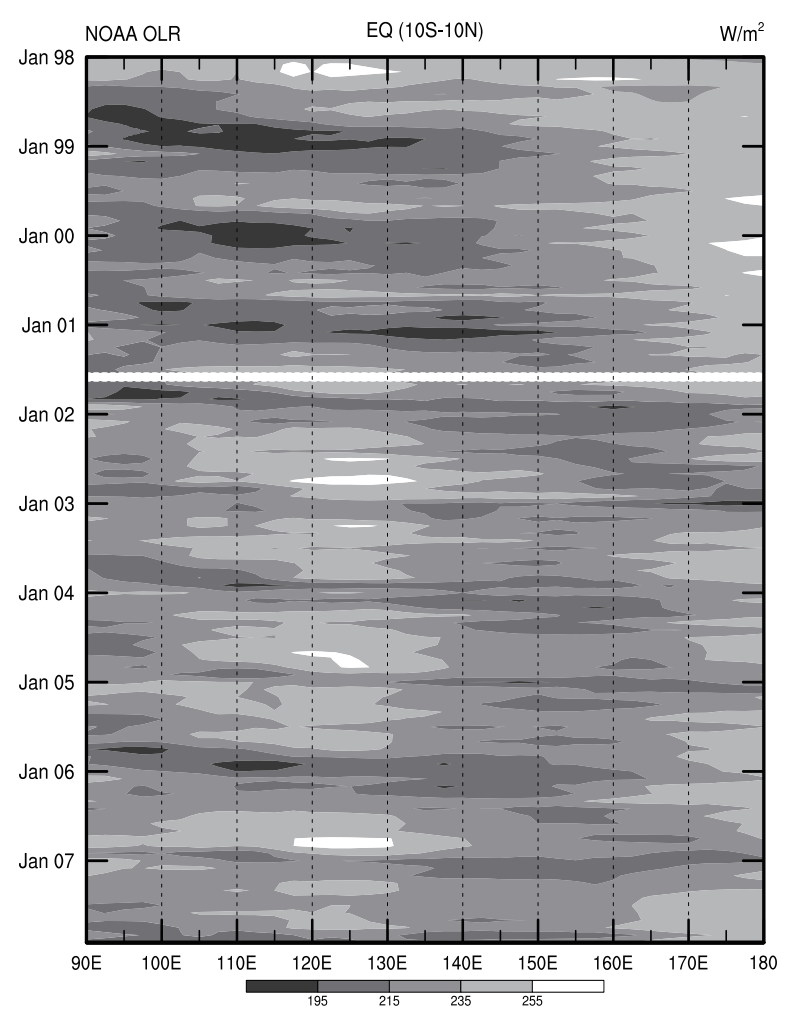

Fig. 1b
Fig. 1b. Time-longitude diagram of OLR (unit: $\mathrm{W} \mathrm{m} \mathrm{m}^{-2}$ ) from $90^{\circ} \mathrm{E}$ to $180^{\circ} \mathrm{E}$, averaged over the equator $\left(10^{\circ} \mathrm{S}\right.$ to $\left.10^{\circ} \mathrm{N}\right)$. The boost, indicated by the white dashed line, occurred in August 2001. The contour intervals are 20 units.

suppressed (enhanced) over the maritime continent (central Pacific) after the boost (bottom panel).

Figure $1 \mathrm{~b}$ depicts the time-longitude section of OLR along the equator from January 1998 to December 2007. The phase shift from La Niña to El Niño can clearly be seen in Fig. 1b. The timing of the boost, denoted by the white dashed line, coincides with the transitional period from the La Niña phase to the El Niño phase. Before the boost, along the equator, active convection with lower OLR values prevails over the maritime continent $\left(90^{\circ} \mathrm{E}\right.$ to $\left.140^{\circ} \mathrm{E}\right)$, whereas convection is suppressed with high OLR values over the central Pacific. After the boost, the regime changes significantly: the positive (negative) anomaly is predominant over the maritime continent (western/central equatorial Pacific).

Figure 2 is the same as Fig. 1, except for the 

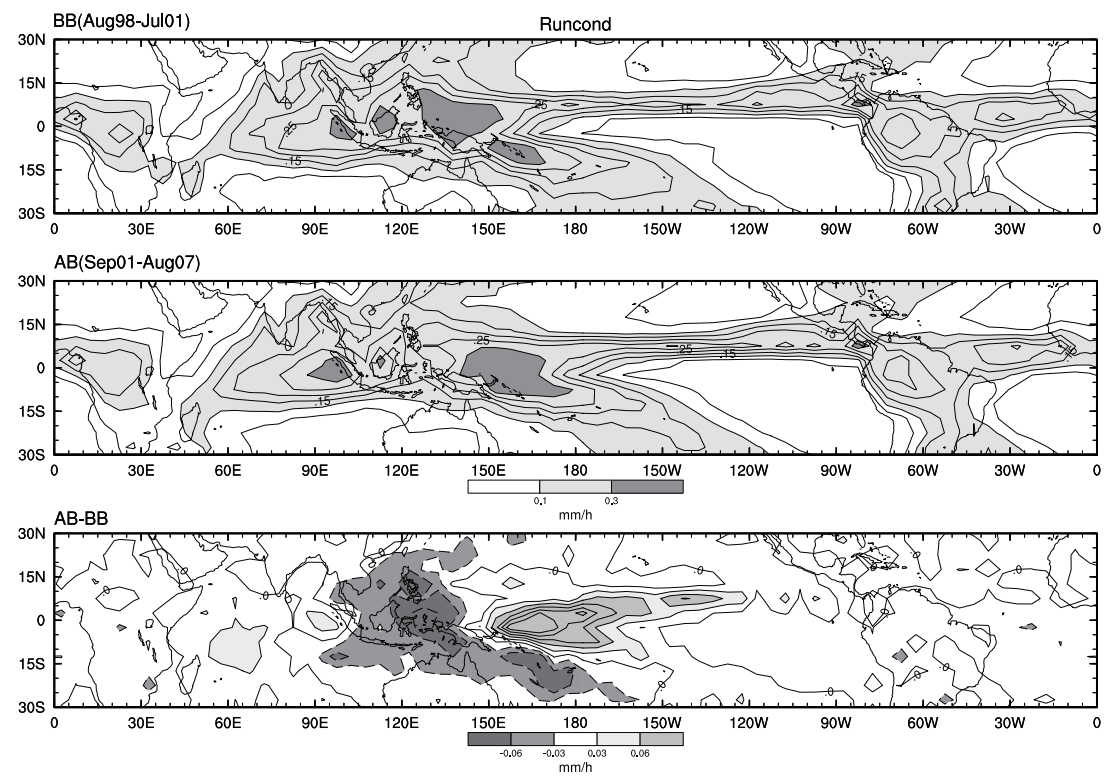

Fig. 2a

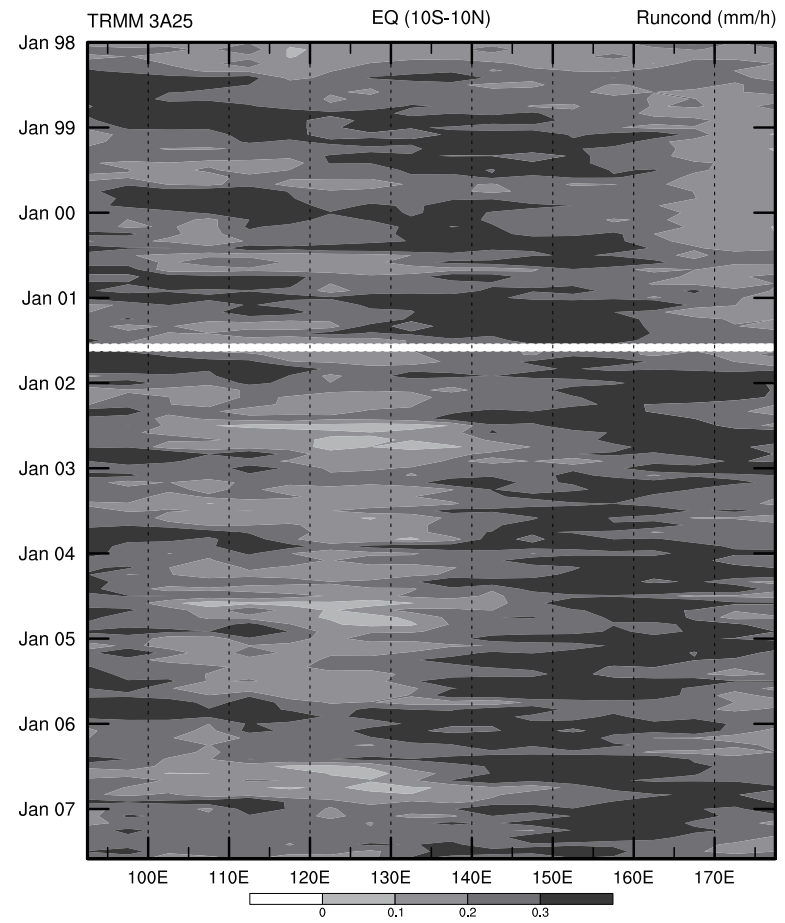

Fig. $2 b$

monthly mean unconditional total rain rate within each $5^{\circ} \times 5^{\circ}$ box in the $3 \mathrm{~A} 25$ dataset. Figure 2 also confirms that the period before the boost (BB) is dominated by the La Niña phase, and the period after
Fig. 2. (a) Same as Fig. 1a, but for the unconditional rain rate $\left(\mathrm{mm} \mathrm{h}^{-1}\right)$ within each $5^{\circ} \times 5^{\circ}$ box. For $\mathrm{BB}$ and $\mathrm{AB}$, dark (light) shading denotes the area of rain rate greater than $0.3 \mathrm{~mm} \mathrm{~h}^{-1}\left(0.1 \mathrm{~mm} \mathrm{~h}^{-1}\right)$ with the contour intervals of $0.05 \mathrm{~mm} \mathrm{~h}^{-1}$. For AB-BB, the contour intervals are 0.03 $\mathrm{mm} \mathrm{h}^{-1}$. (b) Same as Fig. 1b, but for the unconditional rain rate $\left(\mathrm{mm} \mathrm{h}^{-1}\right)$. The contour intervals are $0.1 \mathrm{~mm} \mathrm{~h}^{-1}$.

the boost $(\mathrm{AB})$ corresponds to the El Niño phase. Before the boost (Fig. 2a, top panel), the major area with a rain rate greater than $0.3 \mathrm{~mm} \mathrm{~h}^{-1}$ is located over the equatorial western Pacific $\left(125^{\circ} \mathrm{E}\right.$ to $\left.145^{\circ} \mathrm{E}\right)$. The area with an unconditional rain rate greater than $0.3 \mathrm{~mm} \mathrm{~h}^{-1}$ covers the maritime continent and the Philippines. After the boost (Fig. 2a, middle panel), the major area with a rain rate greater than $0.3 \mathrm{~mm}$ $\mathrm{h}^{-1}$ is located further eastward over the western/ central equatorial Pacific $\left(150^{\circ} \mathrm{E}\right.$ to $\left.165^{\circ} \mathrm{E}\right)$. Thus, the difference in rain rate (BB-AB, Fig. 2a, bottom panel) exhibits an east-west seesaw pattern. A positive peak of $0.15 \mathrm{~mm} \mathrm{~h}^{-1}$ is apparent at $160^{\circ} \mathrm{E}$ near the equator, and a negative peak of $0.09 \mathrm{~mm} \mathrm{~h}^{-1}$ decrease in rain rate can be seen between $120^{\circ} \mathrm{E}$ and $130^{\circ} \mathrm{E}$ along the equator after the boost. Figure $2 \mathrm{~b}$ reveals that before the boost, the unconditional rain rate over the maritime continent (central Pacific) is higher (lower) than normal along the equator. However, after the 
boost, the tendency reverses.

Based on these two figures, we addressed two questions. (1) OLR, which is independent of TRMM boost, exhibits clear interannual variation. The timing of the boost coincides with the regime shift due to the El Niño/La Niña cycle. How do the boost and the transition from La Niña to El Niño appear in the TRMM data? The unconditional rain rate in Fig. 2 also indicates interannual variation. However, it gives only the monthly mean rain rate in the $5^{\circ} \times 5^{\circ}$ box. TRMM 3A25 data provides the frequency of occurrence of 30 rain rate bins, covering wide ranges from very light rain to extremely heavy rain. Thus, it is interesting to see the temporal changes in the rain characteristics. Do changes in the frequency of oc- currences of light rain or heavy rain occur on interannual time-scales and/or before and after the boost? (2) Can we separate the interannual change and the boost impact in the TRMM data?

In this study, these questions are answered mainly by applying EOF analysis and the Lepage Test (Lepage 1971) to the TRMM PR 3A25 dataset for December 1997 to December 2007.

\subsection{Temporal change of global histograms of rain}

Before applying EOF analysis, we first examine the temporal variation of the global $\left(30^{\circ} \mathrm{N}\right.$ to $\left.30^{\circ} \mathrm{S}\right)$ monthly sum of the pixel numbers of the conditional rain rate at $2 \mathrm{~km}$. Figure 3 depicts the monthly total number of pixels with light (top-left) to heavy

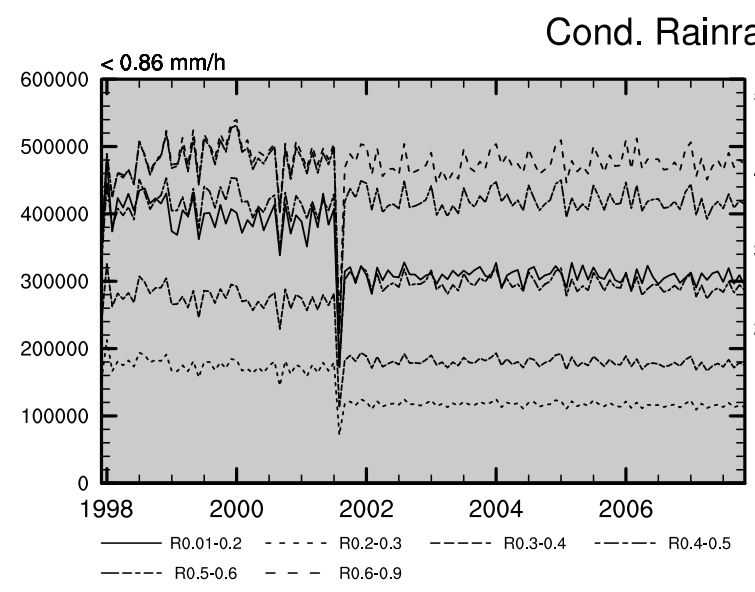

rate at $2 \mathrm{~km}$
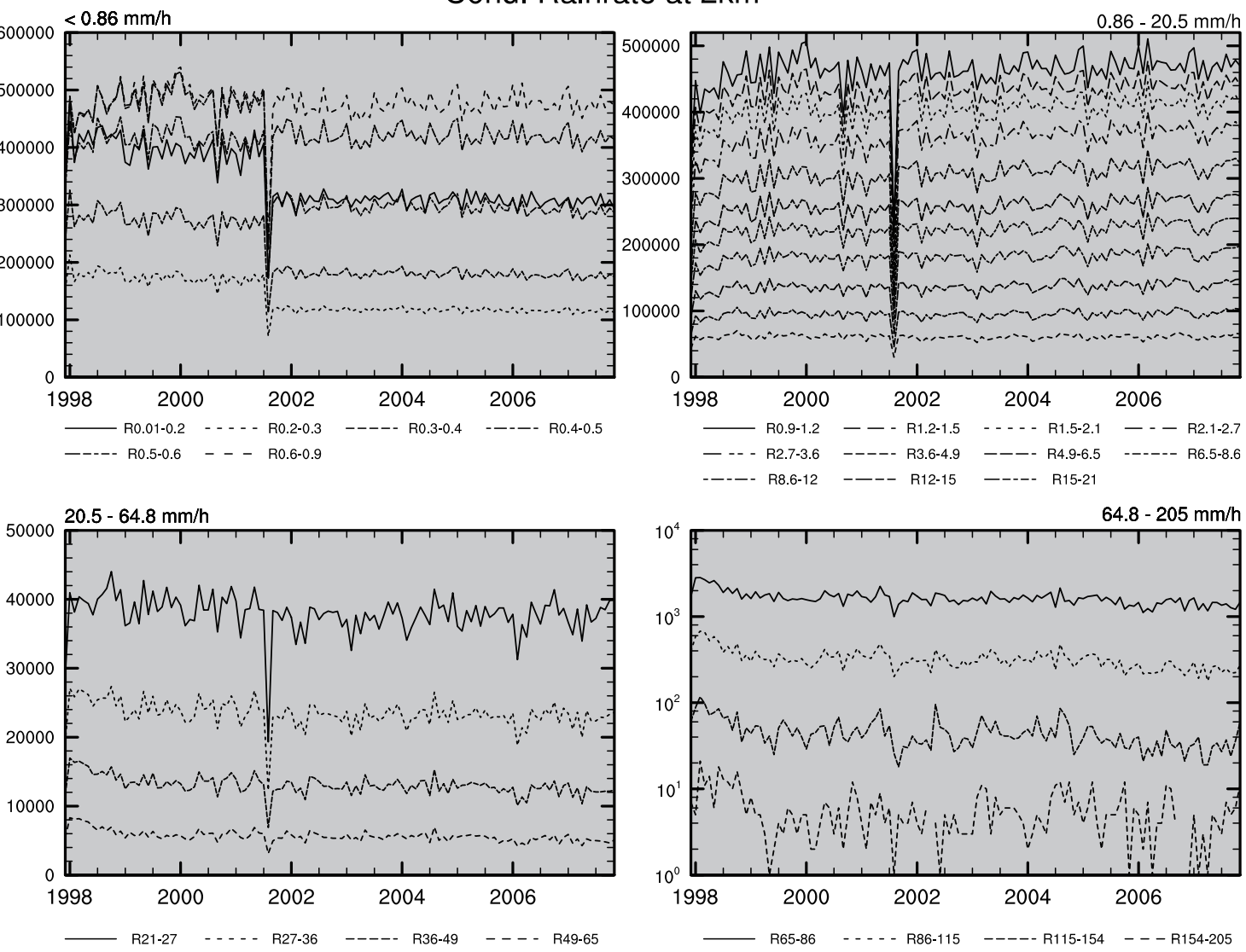

Fig. 3. Total number of pixels of four classes of light (top-left) to heavy (bottom-right) conditional rain rates at $2 \mathrm{~km}$. Each class contains all rain rate bins. For example, at the top-left, the total number of pixels of all five rain rate bins less than $0.65 \mathrm{~mm} \mathrm{~h}^{-1}$ is indicated. The solid line denotes that less than $0.2 \mathrm{~mm} \mathrm{~h}^{-1}$; the short dotted line denotes that between 0.2 and $0.3 \mathrm{~mm} \mathrm{~h}^{-1}$, as indicated at the bottom of the figure. The vertical axes are linear, except for the extremely heavy rain rate histogram class (54.8 to $205 \mathrm{~mm} \mathrm{~h}^{-1}$ ), which is logarithmic. 
Table 2. Threshold rain rates in each class.

\begin{tabular}{ccc}
\hline Class & total/stratiform $\left(\mathrm{mm} \mathrm{h}^{-1}\right)$ & convective $\left(\mathrm{mm} \mathrm{h}^{-1}\right)$ \\
\hline 1 & $\mathrm{R}<0.65$ & $\mathrm{R}<0.86$ \\
2 & $0.65<\mathrm{R}<20.5$ & $0.86<\mathrm{R}<20.5$ \\
3 & $20.5<\mathrm{R}<64.8$ & $20.5<\mathrm{R}<64.8$ \\
4 & $64.8<\mathrm{R}<205$ & $64.8<\mathrm{R}<205$ \\
\hline
\end{tabular}

(bottom-right) conditional rain rates at $2 \mathrm{~km}$ over the globe $\left(30^{\circ} \mathrm{N}\right.$ to $\left.30^{\circ} \mathrm{S}\right)$. The vertical axes are linear, except for the heavy rainfall histogram (64.8 to 205 $\mathrm{mm} \mathrm{h}^{-1}$ ), which has a logarithmic axis. Figure 3 indicates that the number of pixels decreases sharply in the light rain rate histogram bins (top-left, less than $0.65 \mathrm{~mm} \mathrm{~h}^{-1}$ ) after the boost. For rain rate histograms (e.g., convRainH), the 31 bin boundaries are $\left(\mathrm{mm} \mathrm{h}^{-1}\right): 0.01,0.2050482,0.2734362,0.3646330$, $0.4862459,0.6484194,0.8646811,1.153071,1.537645$, $2.050482,2.734362,3.646330,4.862459,6.484194$, $8.646811,11.53071,15.37645,20.50482,27.34362$, $36.46331,48.62460,64.84194,86.46812,115.3071$, 153.7645, 205.0482, 273.4362, 364.6331, 486.2460, 648.4194, and 864.6812 (TRMM PR Team 2005). It is noteworthy that the number does not change much with time for the medium range bins (top-right, 0.65 to $20.5 \mathrm{~mm} \mathrm{~h}^{-1}$ ) before and after the boost. For the strong (bottom-left, 20.5 to $64.8 \mathrm{~mm} \mathrm{~h}^{-1}$ ) and the heavy (bottom-right, 64.8 to $205 \mathrm{~mm} \mathrm{~h}^{-1}$ ) rain rate bins, a gradual decreasing trend is apparent in time.

Figure 3 provides a global sum of the pixel numbers but does not indicate the locality of the changes in rainfall characteristics. EOF analysis is applied to the PR 3A25 dataset to determine the local temporal change and to analyze whether the temporal change (Fig. 3) is universal or not.

\subsection{Dominant spatial and temporal patterns by EOF analysis}

Based on Fig. 3, we classified 30 bins of histogram data into four classes, in order to achieve a similar temporal behavior in each class. These classes slightly differ in the data. Table 2 presents the threshold rain rates in each class. We applied EOF analysis to the histogram data for total conditional rain rate (convRainH) and stratiform rain rate (stratRainH) in the four classes (light to heavy rainfall) at $2 \mathrm{~km}$, to extract the major modes of spatial and temporal

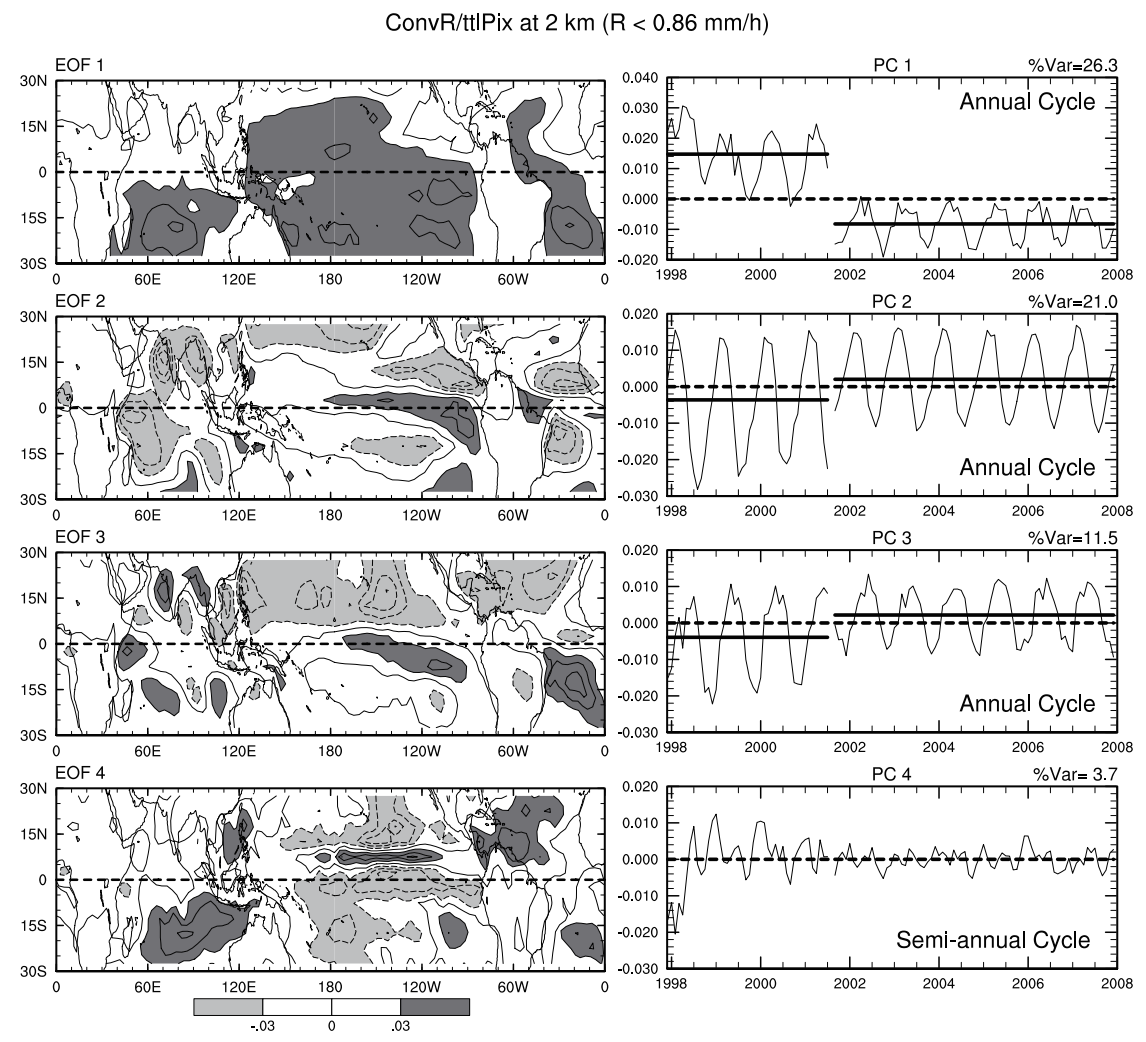

Fig. 4a 
convR/ttIPix at $2 \mathrm{~km}(0.86<\mathrm{R}<20.5 \mathrm{~mm} / \mathrm{h})$
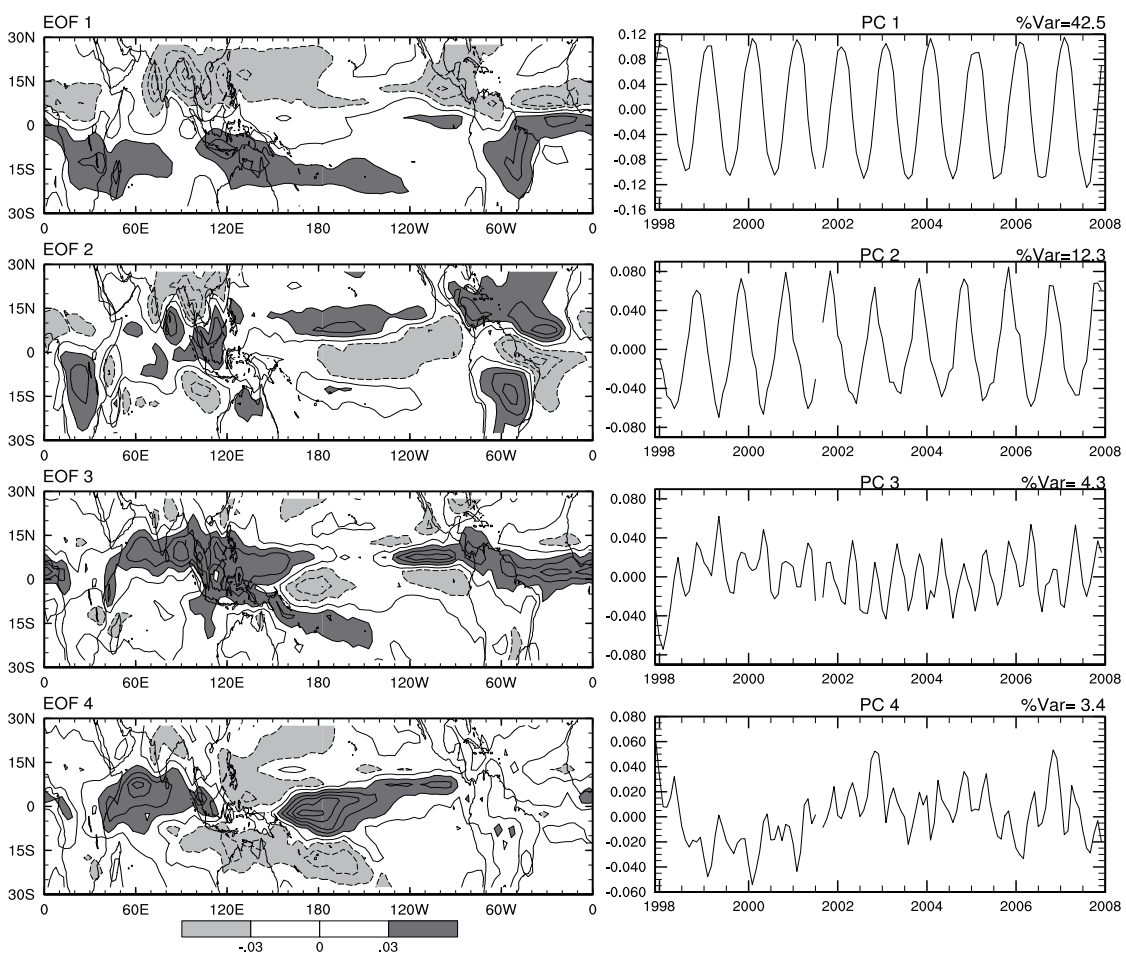

Fig. $4 b$

convR/ttIPix at $2 \mathrm{~km}(20.5<\mathrm{R}<64.8 \mathrm{~mm} / \mathrm{h})$
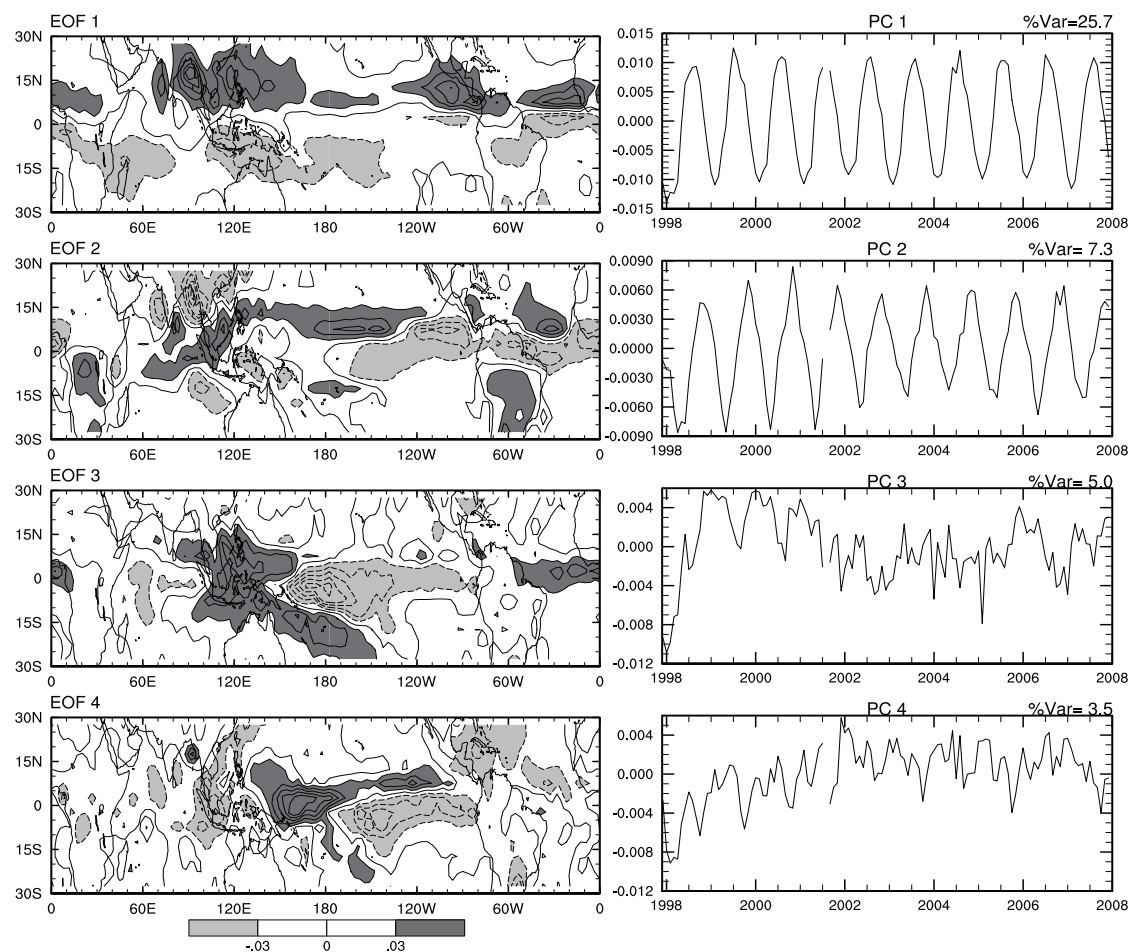

Fig. $4 \mathrm{c}$ 
convR/ttIPix at $2 \mathrm{~km}(\mathrm{R}>64.8 \mathrm{~mm} / \mathrm{h})$
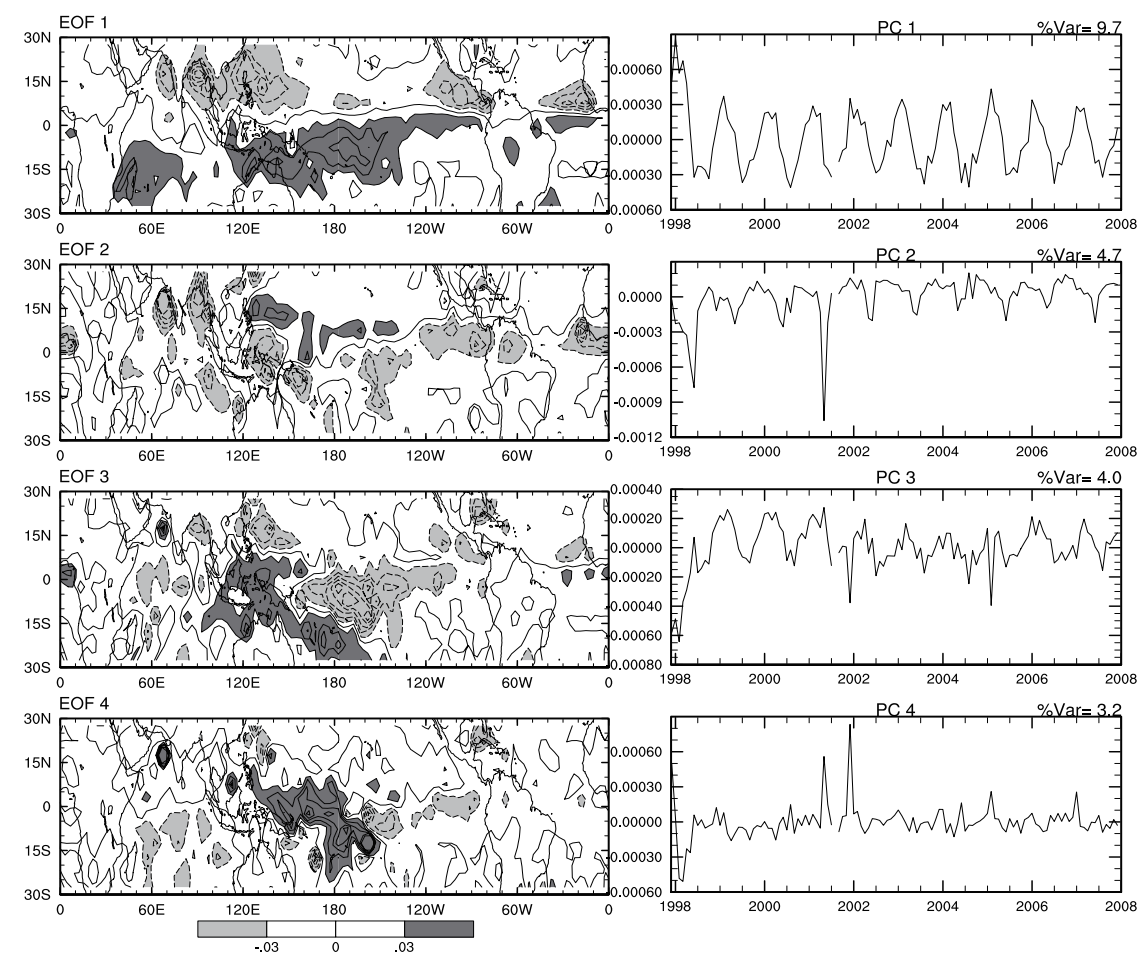

Fig. $4 d$

Fig. 4. (Left) EOF1-4 (from top to bottom) spatial patterns of the number of occurrences of convRainH divided by ttlPix, and (right) the corresponding temporal variations of PC1-4 for the same parameters for (a) light rain rate less than $0.86 \mathrm{~mm} \mathrm{~h}^{-1}$, (b) moderate rain rate between $0.86 \mathrm{~mm} \mathrm{~h}^{-1}$ and $20.5 \mathrm{~mm} \mathrm{~h}^{-1}$, (c) heavy rain rate between $20.5 \mathrm{~mm} \mathrm{~h}^{-1}$ and $64.8 \mathrm{~mm} \mathrm{~h}^{-1}$, and (d) extreme rain rate greater than $64.8 \mathrm{~mm}$ $\mathrm{h}^{-1}$. The variance for each mode, expressed as percentage of the total variance, is indicated at the topright. The contour intervals in the left figures are 0.03 . The dark (light) shading denotes the area greater (smaller) than 0.03 (-0.03). The straight lines in the right-hand figures in Fig. 4a are the baselines of the annual cycle before/after the boost.

variation in the $3 \mathrm{~A} 25$ data over the global tropics. In addition, EOF analysis was applied to SST and OLR.

First, the 10-year monthly mean (not the linear trend) was removed from 10-year monthly variables at each grid point. For the histogram data, we divided the occurrence frequency of total rain rate, for example, by the total TRMM observation numbers (ttlPix), because the occurrence frequency is a function of latitude and drastically increases north of $25^{\circ} \mathrm{N}$ and south of $25^{\circ} \mathrm{S}$. By applying EOF analysis, we obtain the Eigen values, which are related to the variance of associated modes, and the Eigen vectors, which reveal the specific spatial patterns with their temporal coefficients. The fraction of total variance explained by each Eigen vector was also obtained from all
Eigen values and expressed as a percentage of the total variance. In this paper, we present the first four EOFs (EOF1 to 4) because the first four patterns are representative of the dominant temporal or spatial patterns; and in most cases, the fourth EOF (EOF4) explains more than $3 \%$ of the total variance.

\section{a. Number of occurrences of convective rain rates}

Figure 4 depicts EOF1 to 4 (left) with corresponding temporal coefficients (PC1 to 4) (right) for the number of occurrences with convRainH (TRMM PR Team 2005) divided by ttlPix at $2 \mathrm{~km}$ for (a) weak rain rate less than $0.86 \mathrm{~mm} \mathrm{~h}^{-1}$, (b) moderate rain rate between $0.86 \mathrm{~mm} \mathrm{~h}^{-1}$ and $20.5 \mathrm{~mm} \mathrm{~h}^{-1}$, (c) heavy rain rate between $20.5 \mathrm{~mm} \mathrm{~h}^{-1}$ and $64.8 \mathrm{~mm}$ 
a

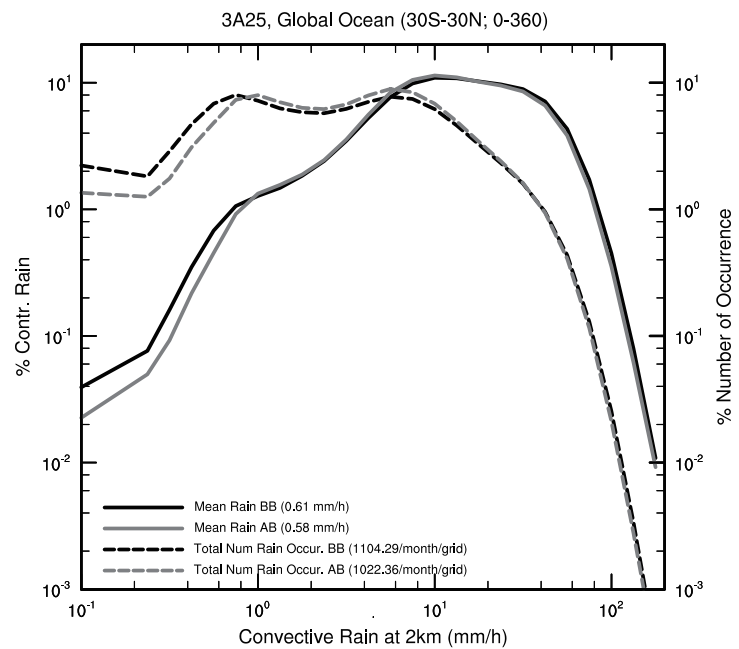

b

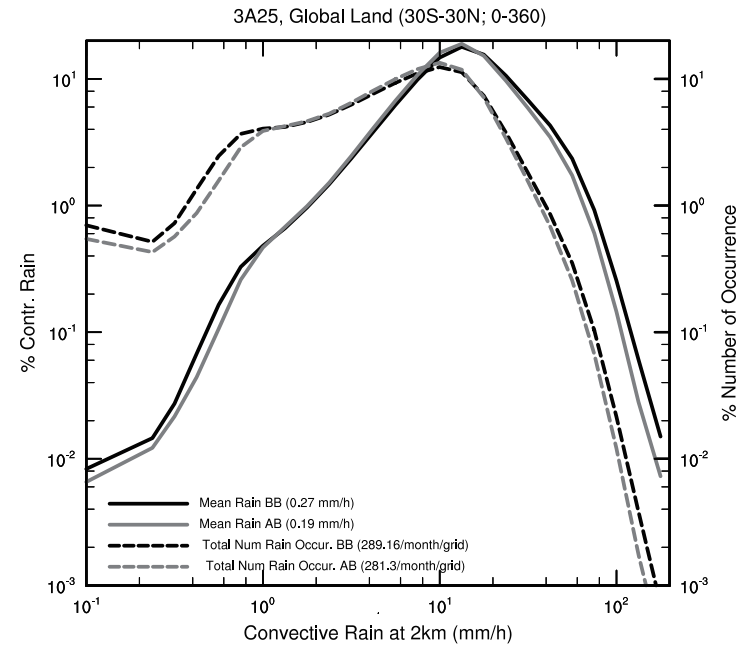

Fig. 5. Percentage of rain contribution (PRC) (solid line) and number of occurrences (dashed line) at 30 rain rate histogram bins before (black) and after (grey) the boost for (a) over the ocean, and (b) over land in $30^{\circ} \mathrm{N}$ to $30^{\circ} \mathrm{S}, 0^{\circ} \mathrm{E}$ to $360^{\circ} \mathrm{E}$.

$\mathrm{h}^{-1}$, and (d) extreme rain rate greater than $64.8 \mathrm{~mm}$ $\mathrm{h}^{-1}$. We removed the data of August 2001, the month of the boost. Thus, the temporal lines are broken due to the boost that occurred in August 2001.

First, we analyzed the EOFs and corresponding PCs for the weak convRainH in Fig. 4a. The first three PCs ( $\mathrm{PC} 1$ to $\mathrm{PC} 3$ ) indicate the annual cycles (wave-like patterns) and an abrupt stepwise change of the baseline of the annual mean (horizontal lines) due to the boost, especially in PC1. Two dominant interannual conditions are evident before and after the boost in Fig. 4a. The first three PCs identify both the annual cycle with different peaks (in April for PC1, February for PC2, and May for PC3) and the abrupt change in the mean state. The spatial pattern of EOF1 (Fig. 4a, left) shows basin-wide positive signs over the Pacific, Atlantic, and southern Indian Ocean. EOF1 corresponds to the impact of the boost, indicating the reduction of the occurrence of the light rain rate over the tropical ocean. EOF1 explains $26.3 \%$ of the total variance. The amplitude of the annual cycle of EOF1 changes its sign from positive to negative after the boost. The corresponding spatial pattern also indicates slightly larger amplitude in the mid-latitudes of both hemispheres with the opposite sign. Combining EOF1 and PC1 reveals that the occurrence of the light rain increases (decreases) in the southern hemisphere ocean in boreal spring (autumn). We do not know why the number reduction is more dominant over the ocean than over the land or why such seasonality in the occurrence of the light rain appears in the southern hemisphere ocean. One speculation for the dominance of the number reduction over land is that we have less chance of light rain over land. To verify this, we analyzed the light rain occurrences over tropical land and ocean separately.

Figure 5 represents the percentage of rain contribution (PRC, solid line) and the number of rain occurrences (PNRO, dashed line) at different convRainH histogram bins before and after the boost (a) over the ocean and (b) over the land. The PRC was computed in the following way. First, we computed the central rain rate $(\mathrm{Rc})$ in each histogram bin. For example, Rc between $115.3071 \mathrm{~mm} \mathrm{~h}^{-1}$ and $153.7645 \mathrm{~mm} \mathrm{~h}^{-1}$ is $133.1546 \mathrm{~mm} \mathrm{~h}^{-1}$, obtained by exp $\left(0.5^{*}(\ln (115.3071)+\ln (153.7645))\right.$. We then summed up the total rain rates in all 30 bins as Rc * PNRO and divided it by the total PNRO to obtain PRC. The total PNRO per $5^{\circ}$ x $5^{\circ}$ grid per month is 1,000 over the ocean and 300 over land. The PRC in the light rain bin over the ocean is also higher than that over land. Thus, we have less chance of light rain (Fig. 4a).

Furthermore, over the ocean, the highest PRC of $10 \%$ is found over the range between $10 \mathrm{~mm} \mathrm{~h}^{-1}$ and $40 \mathrm{~mm} \mathrm{~h}^{-1}$ (Fig. 5a). The mean rain rate is $5 \%$ weaker after the boost for light rain from $0.61 \mathrm{~mm} \mathrm{~h}^{-1}$ to 0.58 $\mathrm{mm} \mathrm{h}^{-1}$. The PRC before the boost is similar to that after the boost, except for the weaker rain rate bins of less than $1 \mathrm{~mm} \mathrm{~h}^{-1}$. In these ranges, the PRC reduction is evident. Also, detailed examination reveals a slight increase in the middle rain rate ranges of 5 to 
$10 \mathrm{~mm} \mathrm{~h}^{-1}$ and a slight decrease in the heavy rain rates ranges of greater than $20 \mathrm{~mm} \mathrm{~h}^{-1}$. The highest PNRO of $6 \%$ to $10 \%$ is found between $0.8 \mathrm{~mm} \mathrm{~h}^{-1}$ and $8 \mathrm{~mm} \mathrm{~h}^{-1}$. The total PNRO is reduced by $0.7 \%$ after the boost, from 1104 to 1022 per $5^{\circ}$ x $5^{\circ}$ grid per month. The histogram of the PNRO before the boost is similar to that after the boost, except for the weaker rain rate bins (less than $1 \mathrm{~mm} \mathrm{~h}^{-1}$ ). In these bins, the PNRO reduction is evident. A slight increase in the middle rain rate bins of 1 to $20 \mathrm{~mm} \mathrm{~h}^{-1}$ can also be seen.

In contrast, over land, a sharp peak in the PRC is apparent at $15 \mathrm{~mm} \mathrm{~h}^{-1}$, reaching $20 \%$ contribution (Fig. 5b). The contribution is larger than $10 \%$ between $10 \mathrm{~mm} \mathrm{~h}^{-1}$ and $20 \mathrm{~mm} \mathrm{~h}^{-1}$ and rapidly becomes smaller in both weaker and heavier rain rate ranges on either side. A reduction of the PRC after the boost is evident in both the heavy and light rain rate bins, with a slight increase in the middle rain rate bin. Similarly, a reduction of the PNRO after the boost is also evident in both the heavy and light rain rate bins, with a slight increase in the middle rain rate bin.

We can easily speculate why light rain occurred less frequently after the boost over ocean and land. However, what causes the reduction in the chance of heavy rain over land after the boost is not known. Three main sources may affect PR rainfall estimation due to the altitude boost (Shimizu et al. 2009). The first is the degradation of sensor sensitivity due to the altitude change. The change causes a reduction in the number of occurrences of light rain rate after the boost over ocean and land. The second is related to the surface clutter effect. Due to the altitude boost, the altitude of observable rain rate off a sub-satellite point is higher; thus, the PR can miss more rain in the lower atmosphere after the boost. We speculate that this may be related to the reduction in the chance of heavy rain rate over land, as the incidence of topographic heavy rainfall events would be high near the mountainous areas. The third is related to the fixed radio pulse frequency of the PR (Takahashi and Iguchi 2004). Before the boost, there were 32 pulses, which harmonized with the radio reception intervals. However, after the boost, although there were still 32 pulses, the last one mismatched the transmission and reception angles, producing anti-symmetric rain rates in the cross-track direction.

In Fig. 4a, EOF2 may correspond to the boreal summer component and explain $21.0 \%$ of the total variance. Even though the spatially negative pattern of EOF2 is widely distributed globally over the ocean, the phase in the temporal coefficient (Fig. 4a, right) has a negative peak in boreal summer. Therefore, light rain occurs more often over the Arabian Sea or the Bay of Bengal, and is related to the Indian summer monsoon. EOF3, which explains $11.5 \%$ of the total variance, is an equinox mode with peak amplitudes in May and November, and would be the same annual mode as EOF2. The temporal coefficient of EOF4 (Fig. 4a, bottom-right) indicates a weak semi-annual cycle. We do not know much about the physical meaning of this mode, but we have observed a semi-annual fluctuation of the Intertropical Convergence Zone (ITCZ) over the central and eastern Pacific along $5^{\circ}$ to $10^{\circ} \mathrm{N}$. The ITCZ is active in January and July, and inactive in May and November. Interestingly, there are no ENSO-related modes in the first four EOFs for the number of occurrences of weak convRainH at $2 \mathrm{~km}$ (Fig. $4 \mathrm{a}$ ).

Next, we analyzed the moderate convRainH (Fig. 4b). The first two EOFs represent the annual cycle, the third EOF represents the semi-annual cycle, and the fourth EOF corresponds to the pseudo-ENSO mode. In the moderate convRainH, no signature of abrupt change occurs due to the boost in the PCs, but a small baseline increase does occur in the annual mean in PC2.

The first two EOFs of heavy convRainH in Fig. 4c are similar to those of moderate convRainH (Fig. 4b). The spatial patterns and temporal coefficients are also similar for the two groups. Also, a small baseline increase in the annual mean occurred in PC2. However, no semi-annual cycle was apparent in the third group. Both (EOF3, PC3) and (EOF4, PC4) represent pseudo-ENSO modes with maximum amplitudes near the dateline in the tropics.

The last group of extreme rain rate greater than $64.8 \mathrm{~mm} \mathrm{~h}^{-1}$ (Fig. 4d) exhibits several spurious peaks in the temporal coefficients, mainly due to the small sampling numbers in this group. However, closer examination of the spatial patterns reveals that the first two EOFs may correspond to the annual cycle, and $(\mathrm{EOF} 3, \mathrm{PC} 3)$ represents the pseudo-ENSO mode.

\section{b. Test for discontinuous change in convective rain rates}

The Lepage test (Lepage 1971; Yonetani 1992) was applied to determine if we could detect any discontinuous change in the time series in PC1-4 of the convRainHs in Fig. 4. We chose this test based on the study by Hirakawa (1974), which indicated that the Lepage test is the most robust of 11 different tests. 
ConvR/ttIPix at $2 \mathrm{~km}(\mathrm{R}<0.86 \mathrm{~mm} / \mathrm{h})$
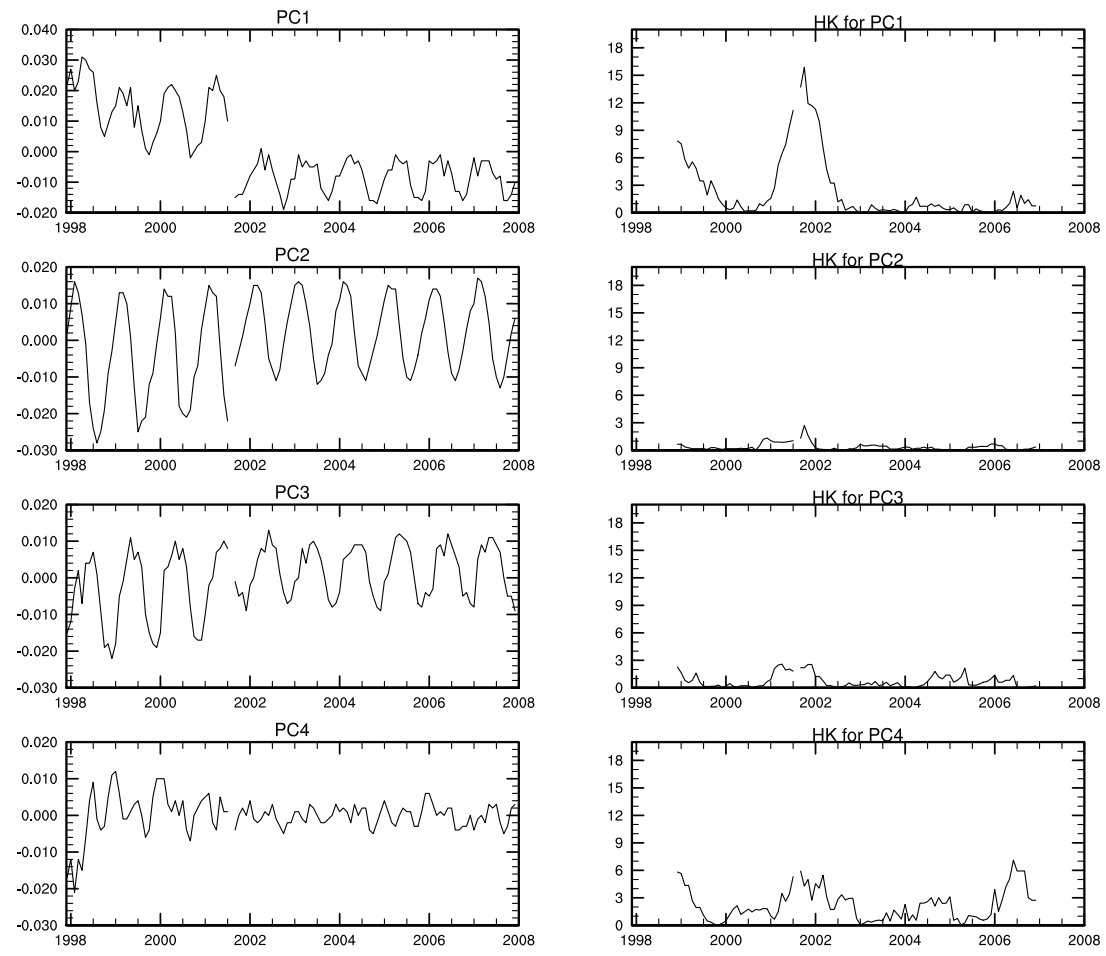

Fig. 6a
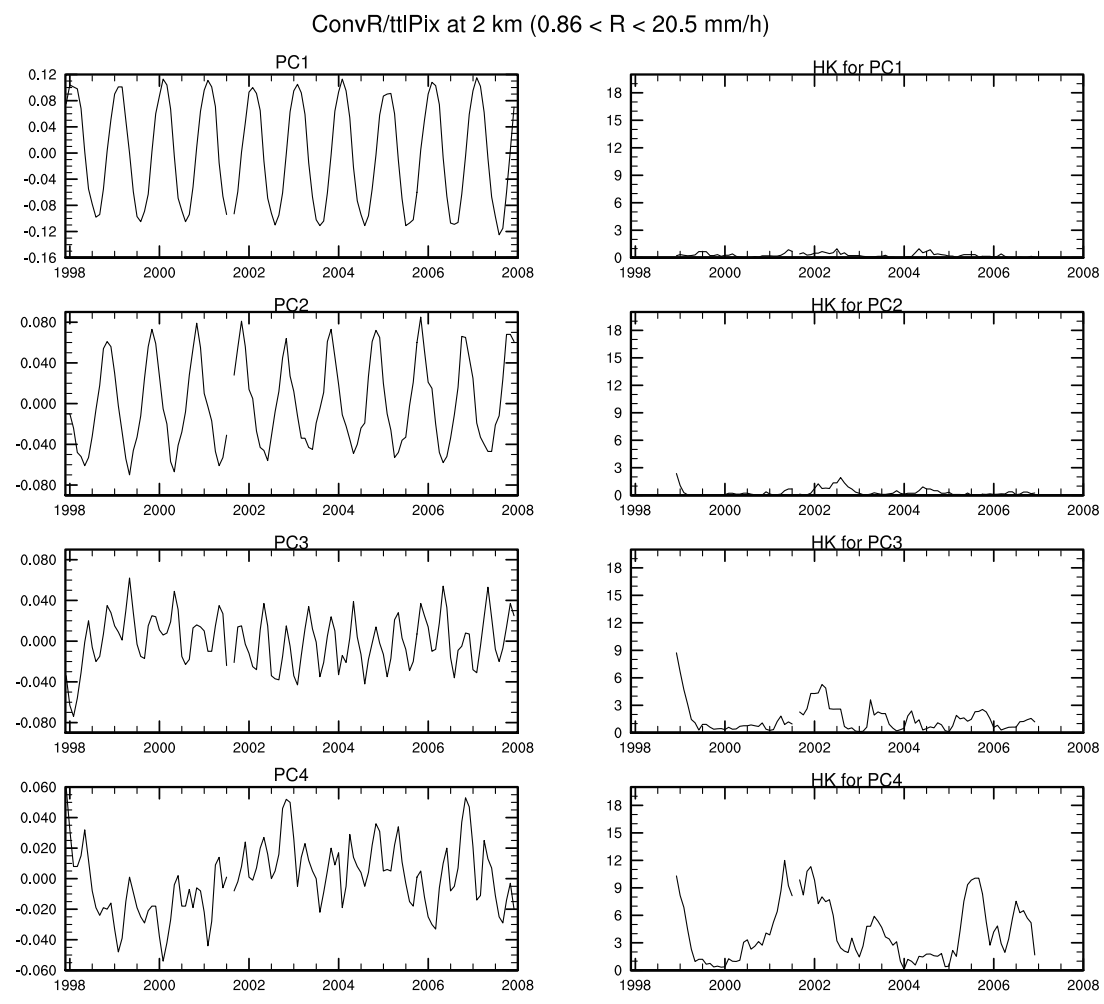

Fig. $6 \mathrm{~b}$ 

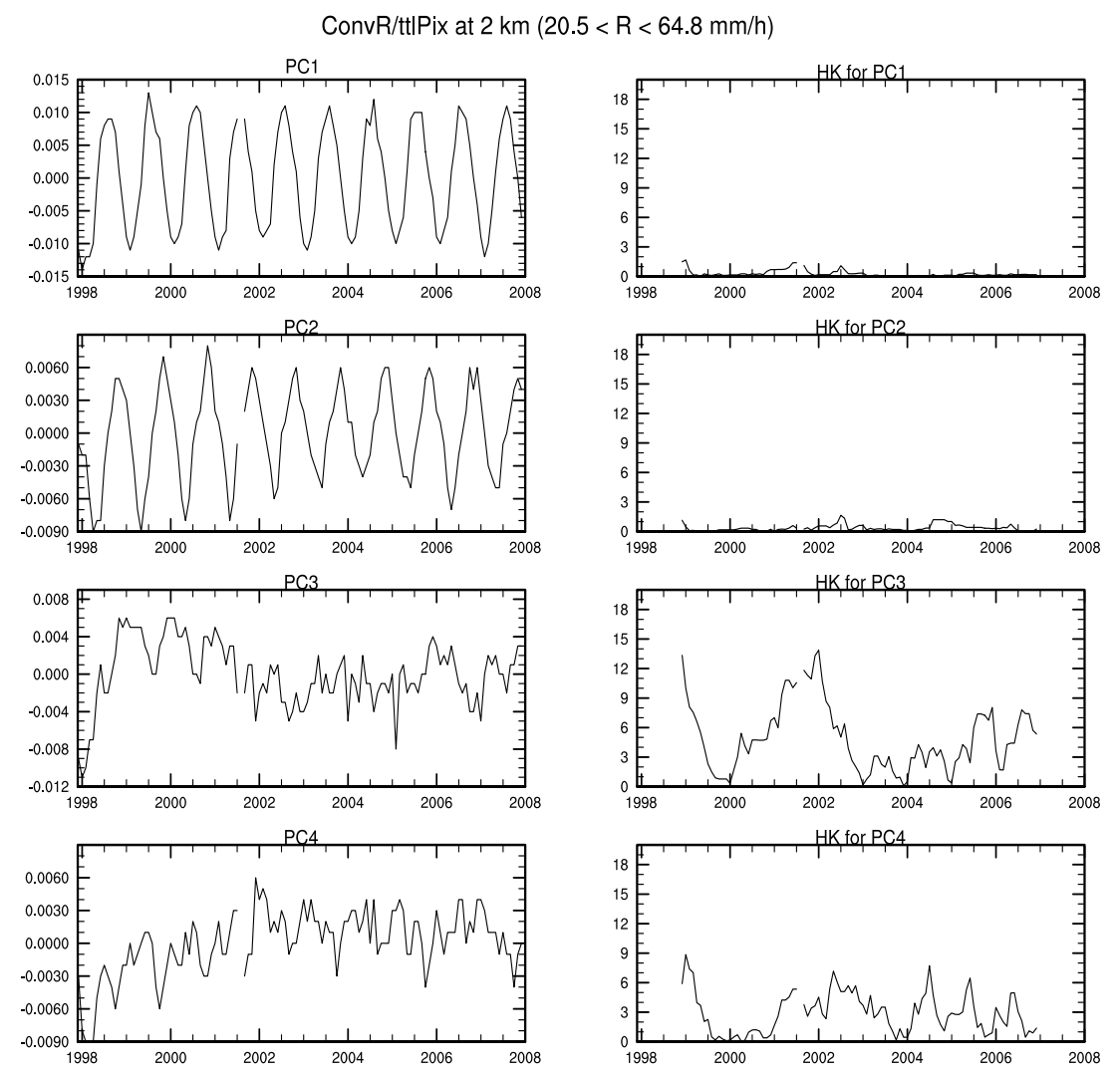

Fig. 6c

Fig. 6. Lepage test results for PC1-4 in Figs. 4a(a), 4b(b), and 4c(c). (Left) Same as PC1-4 in Fig. 4a-c.

(Right) Lepage statistic, HK, for PC1-4 in Fig. 4a-c.

The test statistic HK in the Lepage test is a sum of the squares of the standardized Wilcoxon's and Ansari-Bradley's statistics. If both samples are greater than 10, then HK follows the chi-square distribution with two degrees of freedom. Thus, when HK exceeds 5.991 (9.210), two samples are significantly different at the $5 \%(1 \%)$ level.

Figure 6 presents the result of the Lepage test for PC1-4 of Fig. 4a-c. For the light rain rate (Fig. 6a, R< $\left.0.86 \mathrm{~mm} \mathrm{~h}^{-1}\right)$, the peak value of $\mathrm{HK}$ for PC1 exceeds 15 (less than $0.1 \%$ significant level) in late 2001, due to the impact of the boost. Despite mean shifts of the annual cycle in the time series of PC2 and PC3, the Lepage test does not indicate significance. For the light to heavy rain rate (Fig. $6 \mathrm{~b}, 0.86 \mathrm{~mm} \mathrm{~h}^{-1}<\mathrm{R}<$ $20.5 \mathrm{~mm} \mathrm{~h}^{-1}$ ), the peak for PC4 exceeds 10 in June 2001. The timing is similar to the boost, but the temporal change of PC4 is gradual, and the spatial pattern of EOF4 of Fig. $4 \mathrm{~b}$ is for the pseudo-ENSO mode. Thus, this large HK is not due to the boost but is the result of the transition periods from the La Niña phase to the El Niño phase. Two other peaks in HK occurred, one in January 1999 and one in August 2005. These peaks may be related to the El Niño event in 1998 and the La Niña event in 2005. For the heavy rain rate (Fig. $6 \mathrm{c}, 20.5 \mathrm{~mm} \mathrm{~h}^{-1}<\mathrm{R}<64.8 \mathrm{~mm}$ $\mathrm{h}^{-1}$ ), two peaks greater than 10 for PC3 can be seen, one in January 1999 and another in January 2002. The high HK values are not related to the boost, but to the transitions between the El Niño phase and the La Niña phase.

\section{c. Number of occurrences of stratiform rain rates}

Figure 7 depicts the first four EOFs and PCs of the occurrence number of stratRainH, divided by ttlPix at $2 \mathrm{~km}$. First we analyze the weak rain rate group in Fig. 7a. In PC1 (top-right), a reduction in the amplitude of the annual cycle occurs after the boost. Be- 
fore the boost, the amplitude of the annual cycle is larger than that after the boost. From EOF1 (top-left), an anti-symmetric pattern can be seen with respect to the equator, with a positive (negative) peak in the Southern (Northern) Hemisphere. A positive (negative) peak is observed in the time series (top-right) in boreal winter (summer). Thus, we have a greater chance of light stratiform rain in boreal summer (winter) in the Northern (Southern) Hemisphere. It is interesting to note that a peak is observed over land in this mode, which differs from Fig. 4a.

EOF2 also indicates an annual cycle with a peak in the temporal coefficient in boreal spring, suggesting that this mode is an equinox mode. This mode also exhibits a gradual reduction of amplitude after the boost. This reduction is related to the boost. EOF3 is the interannual mode that is identified as the pseudoENSO mode. EOF3 exhibits a negative peak over the maritime continent and a positive peak over the equatorial western/central Pacific centered at $160^{\circ} \mathrm{E}$ to $170^{\circ} \mathrm{W}$. The temporal variation associated with EOF3 is positive in early 1998, then becomes negative until 2001 and again becomes positive after 2002. We overlay the temporal variation of the NINO-3 SST variation obtained from the JMA on PC3 as a dashed line (third from the top-right). Both the time series of the PC3 and the ENSO index coincide well and are in phase. EOF4 is considered as the 1998 ENSO mode because the amplitude of PC4 is large in early 1998. The spatial pattern of EOF4 (bottom-left) indicates the El Niño event in 1998. As is documented by Ashok et al. (2007), EOF4 represents the canonical ENSO mode, and EOF3 represents the pseudo-ENSO mode.

In the moderate rain rate of stratiform rain in Fig. $7 \mathrm{~b}$, we find that EOF1 to EOF4 patterns are similar to those in Fig. 7a. EOF1 and EOF2 indicate the annual cycle, with $31.6 \%$ and $8.6 \%$ of the total variance; EOF3 indicates the ENSO cycle; and EOF4 indicates the pseudo-ENSO cycle. No amplitude reduction occurs in $\mathrm{PC} 1$.

The heavy stratRainH in Fig. $7 \mathrm{c}$ indicates that EOF1 exhibits the annual cycle with a large amplitude over the Bay of Bengal, the western North Pacific, the eastern North Pacific and the northeastern Atlantic in boreal summer. This mode has large

StratRainH/tt|Pix at $2 \mathrm{~km}(\mathrm{R}<0.65 \mathrm{~mm} / \mathrm{h})$
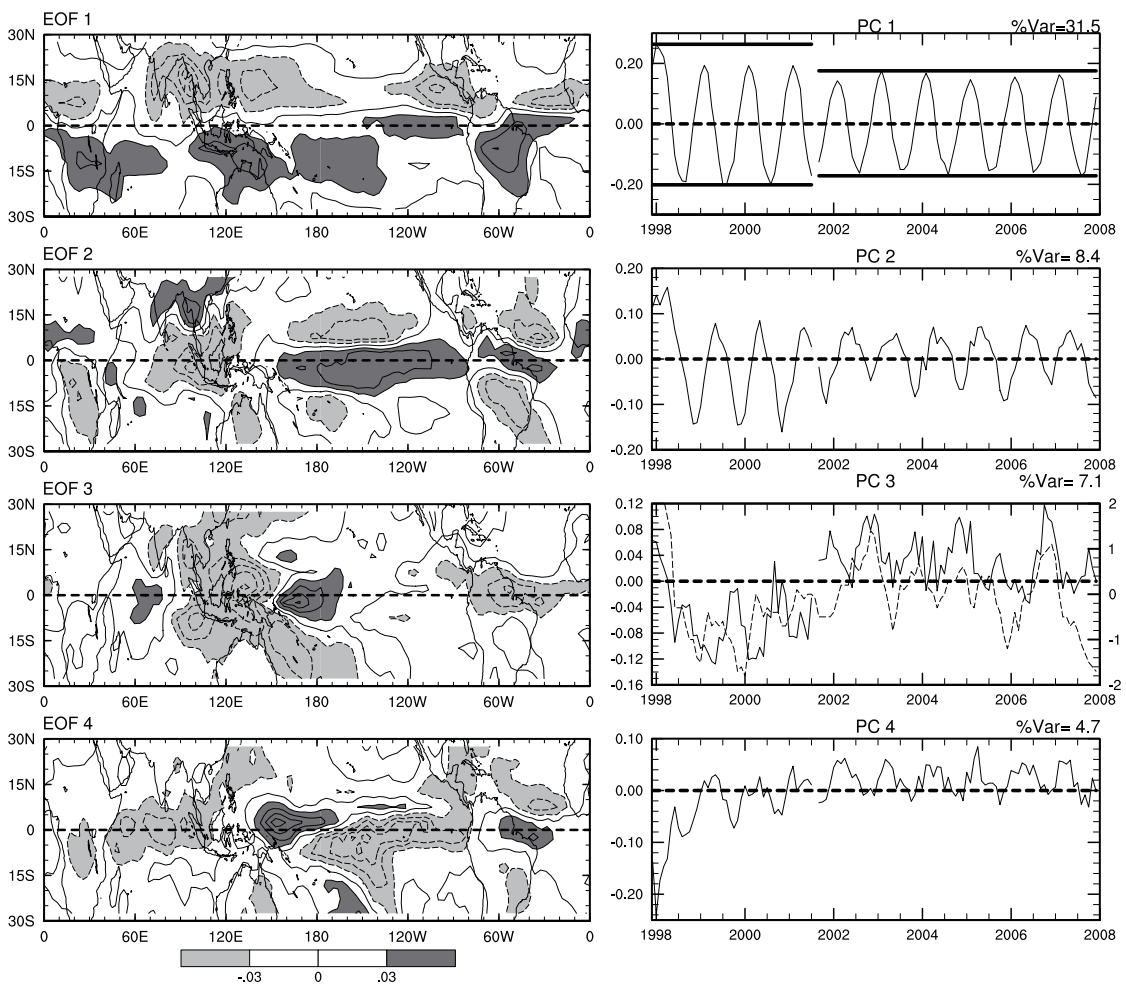

Fig. 7a 
StratRainH/ttIPix at $2 \mathrm{~km}(0.65<\mathrm{R}<20.5 \mathrm{~mm} / \mathrm{h})$
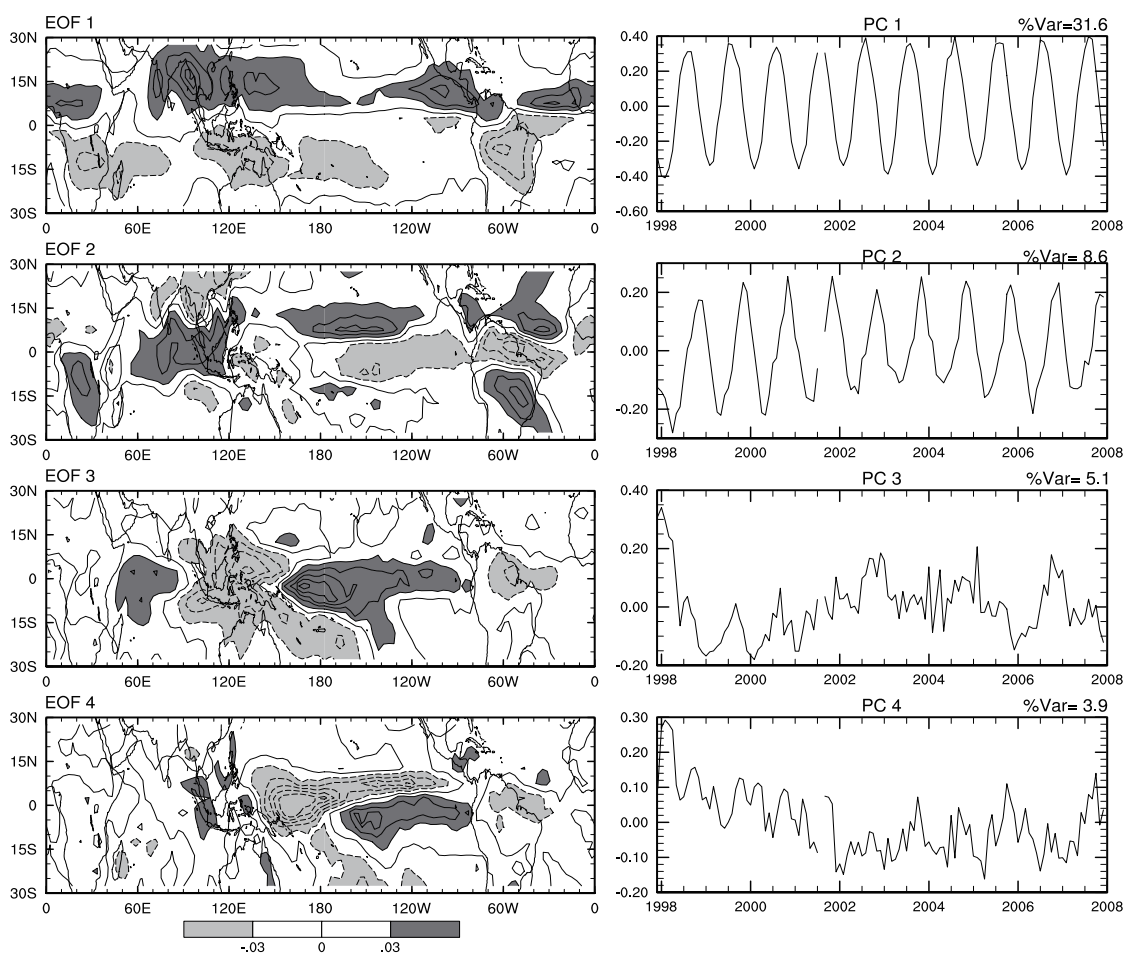

Fig. $7 b$
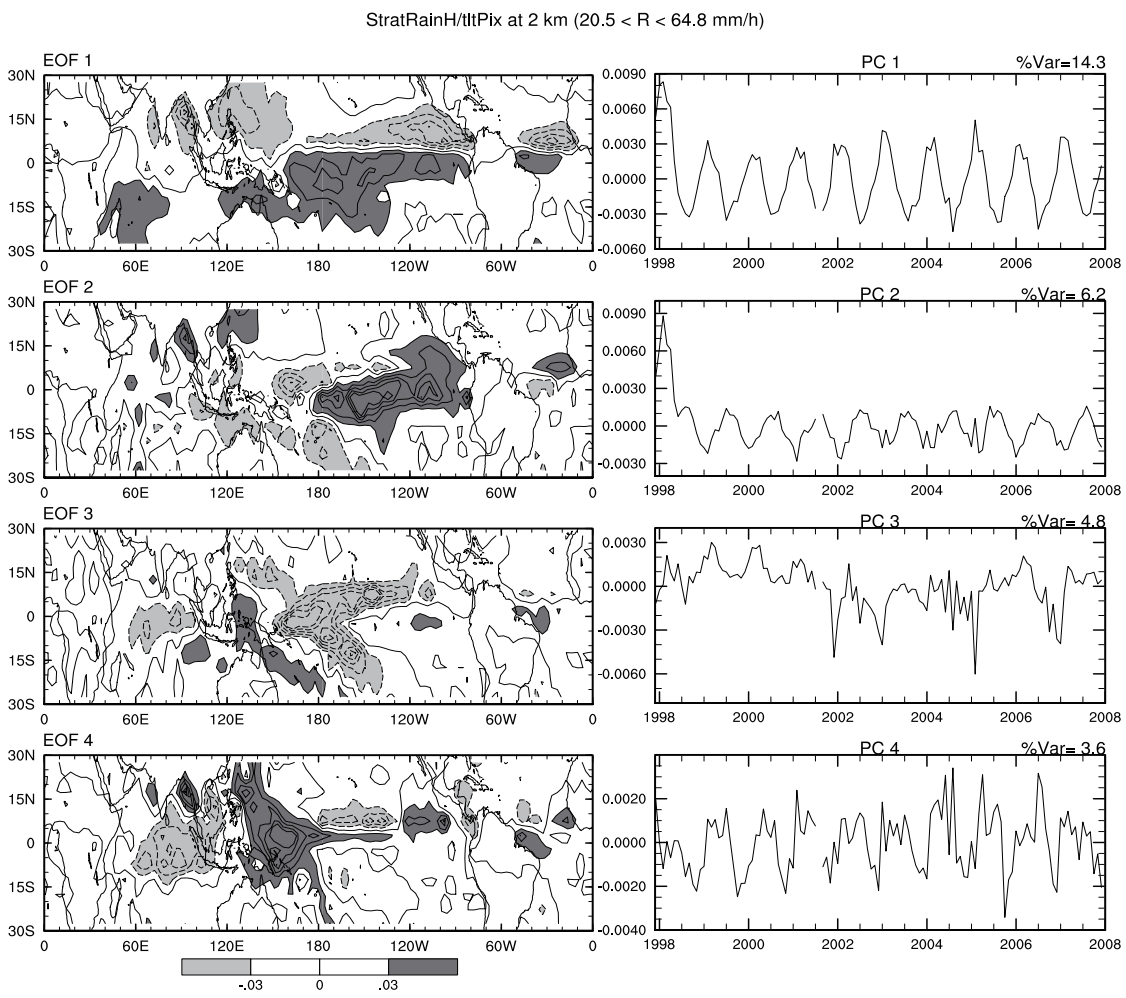

Fig. 7c 


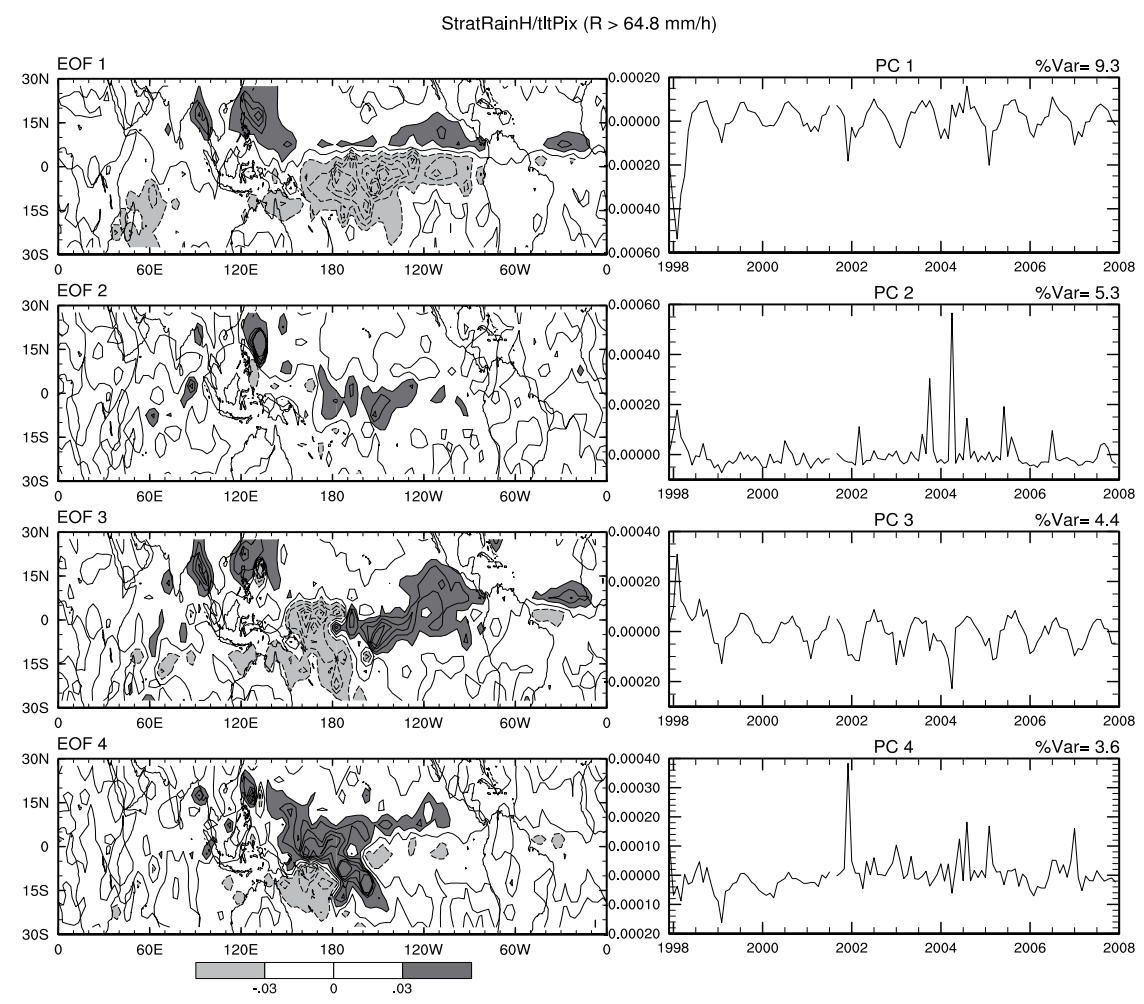

Fig. 7d

Fig. 7. Same as Fig. 4, except for the stratiform rain rate (stratRainH), divided by ttlPix at $2 \mathrm{~km}$. The threshold rain rate in the first class is $0.65 \mathrm{~mm} \mathrm{~h}^{-1}$. The straight lines in the top-right figure (PC1) in Fig. $7 \mathrm{a}$ indicate the ranges of the annual cycle before/after the boost. The dashed line in PC3 in Fig. 7a indicates the SST temperature variation at the Niño-3 area in the JMA analysis.

amplitude in early 1998. EOF2 indicates the weak annual cycle with large amplitude in early 1998. The maximum positive (negative) amplitude in boreal summer (winter) in PC2 suggests that more rainfall is observed over the equatorial eastern Pacific in boreal summer and over the central Pacific in boreal winter. EOF3 is similar to EOF2, but with no signals over the equatorial central Pacific (EOF3 of Fig. 6c). However, compared to EOF2, much stronger amplitude is observed over the maritime continent. With a change in sign, EOF3 and PC3 in Fig. 7c coincide well with those in Fig. 7b. EPF4 also represents the annual cycle. However, the cycle, as seen in Fig. 7c, is complicated or irregular in time.

The extreme stratRainH $\left(64.8 \mathrm{~mm} \mathrm{~h}^{-1}<\mathrm{R}<205\right.$ $\mathrm{mm} \mathrm{h}^{-1}$ ) in Fig. $7 \mathrm{~d}$ reveals that the contributions to the total variance decrease, with only $9.3 \%$ for EOF1, $5.3 \%$ for $\mathrm{EOF} 2,4.4 \%$ for $\mathrm{EOF} 3$, and $3.6 \%$ for EOF4, indicating that the predominance of these four pat- terns is not significant. Occasionally, sharp and sudden jumps are observed in EOF2 and EOF4, and the temporal coefficients are close to zero, suggesting that these modes have a localized character in time and space. The (EOF1, PC1) exhibits similar spatial and temporal variation, as in (EOF1, PC1) of heavy stratRainH (Fig. 7c). Also, (EOF3, PC3) exhibits spatial and temporal variation similar to that of (EOF2, PC2) of heavy stratRainH (Fig. 7c).

\section{d. Number of occurrences of total rain rates}

Figure 8 depicts the EOFs of the number of occurrences of the total rain rate, rainH, divided by ttlPix at $2 \mathrm{~km}$. The EOFs in Fig. 8a are very similar to those in Fig. 7a. For the light rain rate, indicated in PC1 of Fig. 8a (top-right), a reduction in the amplitude of the annual cycle occurs after the boost. Before the boost, the amplitude of the annual cycle is larger than that after the boost. In EOF1 (top-left), an 
anti-symmetric pattern is observed with respect to the equator, with a positive (negative) peak in the Northern (Southern) Hemisphere. A positive (negative) peak in the time series (top-right) is observed in boreal summer (winter). Thus, we have a greater chance of light rain in boreal summer (winter) in the Northern (Southern) Hemisphere. The peak over land in this mode makes it different from that in Fig. 4a.

In $\mathrm{PC} 2$, a reduction in the amplitude of the annual cycle occurred after the boost. (EOF3, PC3) has an interesting feature: EOF3 indicates the pseudo-ENSO mode, but PC3 appears to be an abrupt change due to the boost. A comparison of EOF3 in Fig. 8a with EOF3 in Fig. 7a indicates that this mode is the pseudo-ENSO mode. PC4 (bottom-right) indicates the canonical ENSO mode.

For moderate total rain rate in Fig. $8 b$, we find that EOF1 through EOF3 patterns are similar to those in Fig. 8a. EOF1 and EOF2 indicate the annual cycle; EOF3 indicates the ENSO cycle; and EOF4 mode indicates the pseudo-ENSO cycle. However, a slight amplitude increase is apparent in the annual cycle after the boost in PC1. For the heavy rain rate
(Fig. 8c), all four EOFs are similar to those in Fig. $8 \mathrm{~b}$ and Fig. $7 \mathrm{~b}$, but with a change of the sign for some of them.

For the extreme rain rate (Fig. 8d), the first two EOFs indicate the annual cycle, but the amplitude of the annual cycle decreases after mid-1998. In early 1998, PC1 and PC2 are out of phase, but subsequently $\mathrm{PC} 1$ and $\mathrm{PC} 2$ are in phase. This result indicates that chances of extreme rain events are reduced over the equatorial central/eastern Pacific while constantly existing in boreal summer over the Arabian Sea, the Bay of Bengal, and western North Pacific. (Over these regions, the spatial coefficients of EOF1 and EOF2 are of the same sign.)

\section{e. $O L R$}

Figure 9a depicts the first four EOF patterns (left) with the temporal coefficients (right) for the OLR. EOF1 indicates the annual cycle. EOF2 and EOF3 indicate the annual cycle modulated by the ENSO cycle. These three modes are similar to the first three modes in the middle to heavy convective (Figs. 4b and $4 \mathrm{c}$ ), stratiform (Figs. $7 \mathrm{~b}$ and $7 \mathrm{c}$ ), and total rain

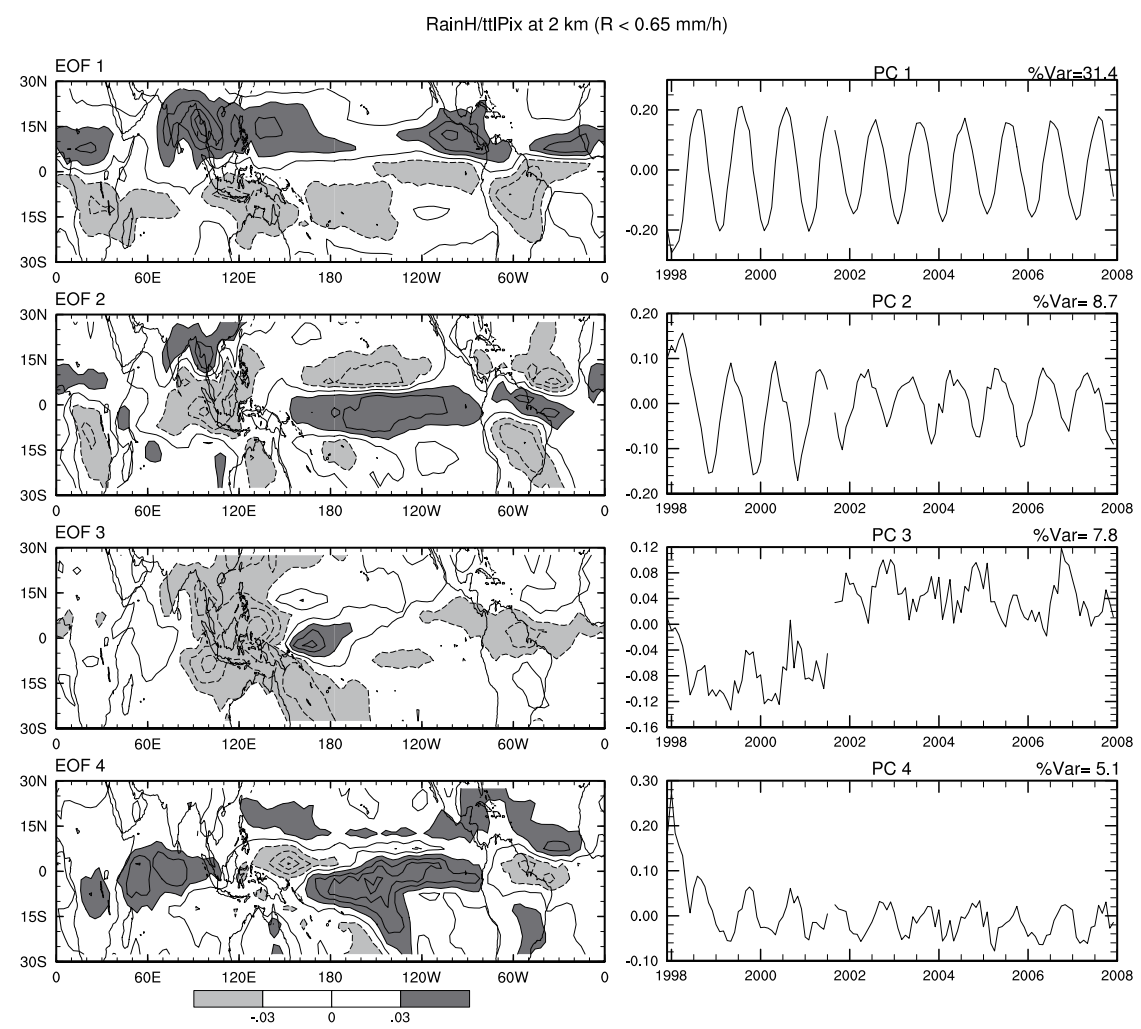

Fig. 8a 
RainH/ttIPix at $2 \mathrm{~km}(0.65<\mathrm{R}<20.5 \mathrm{~mm} / \mathrm{h})$
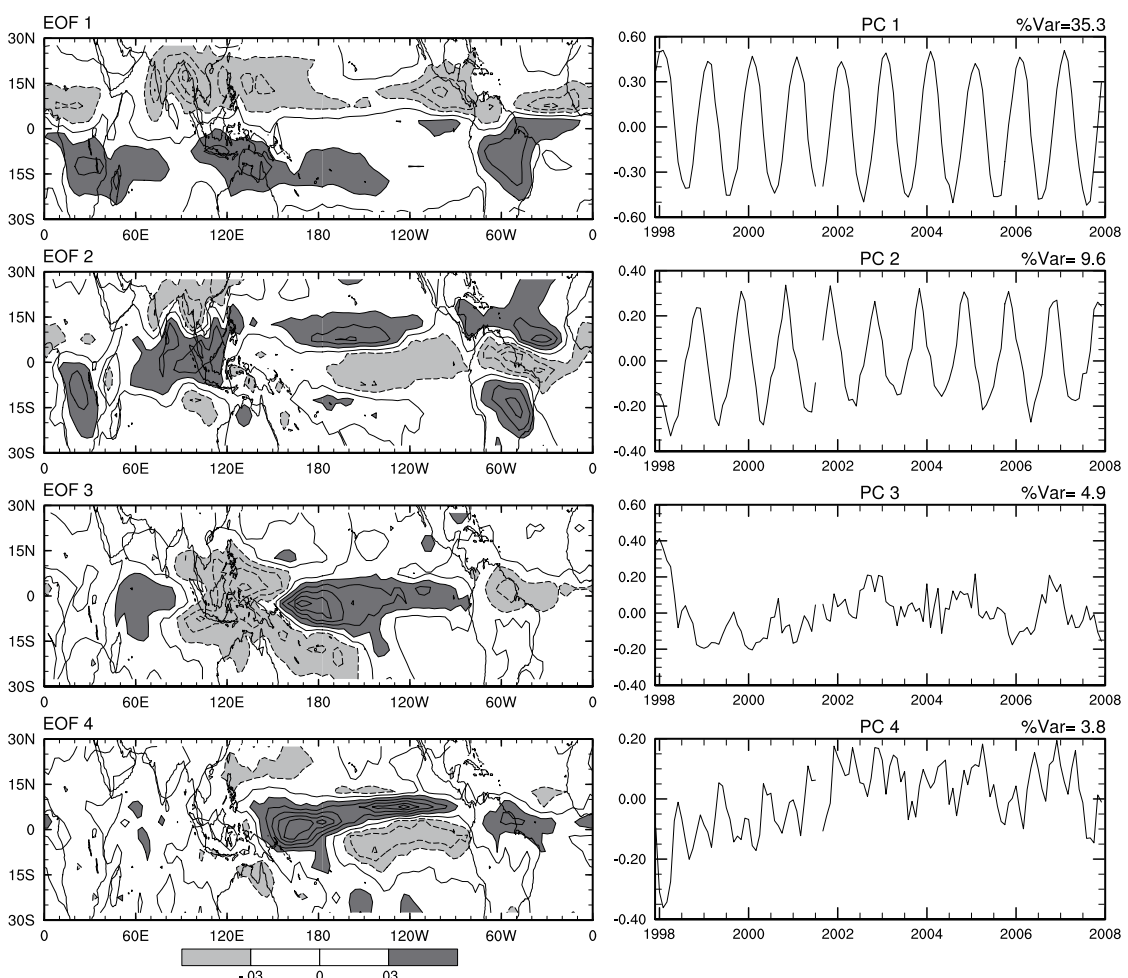

Fig. 8b

RainH/ttIPix at $2 \mathrm{~km}(20.5<\mathrm{R}<64.8 \mathrm{~mm} / \mathrm{h})$
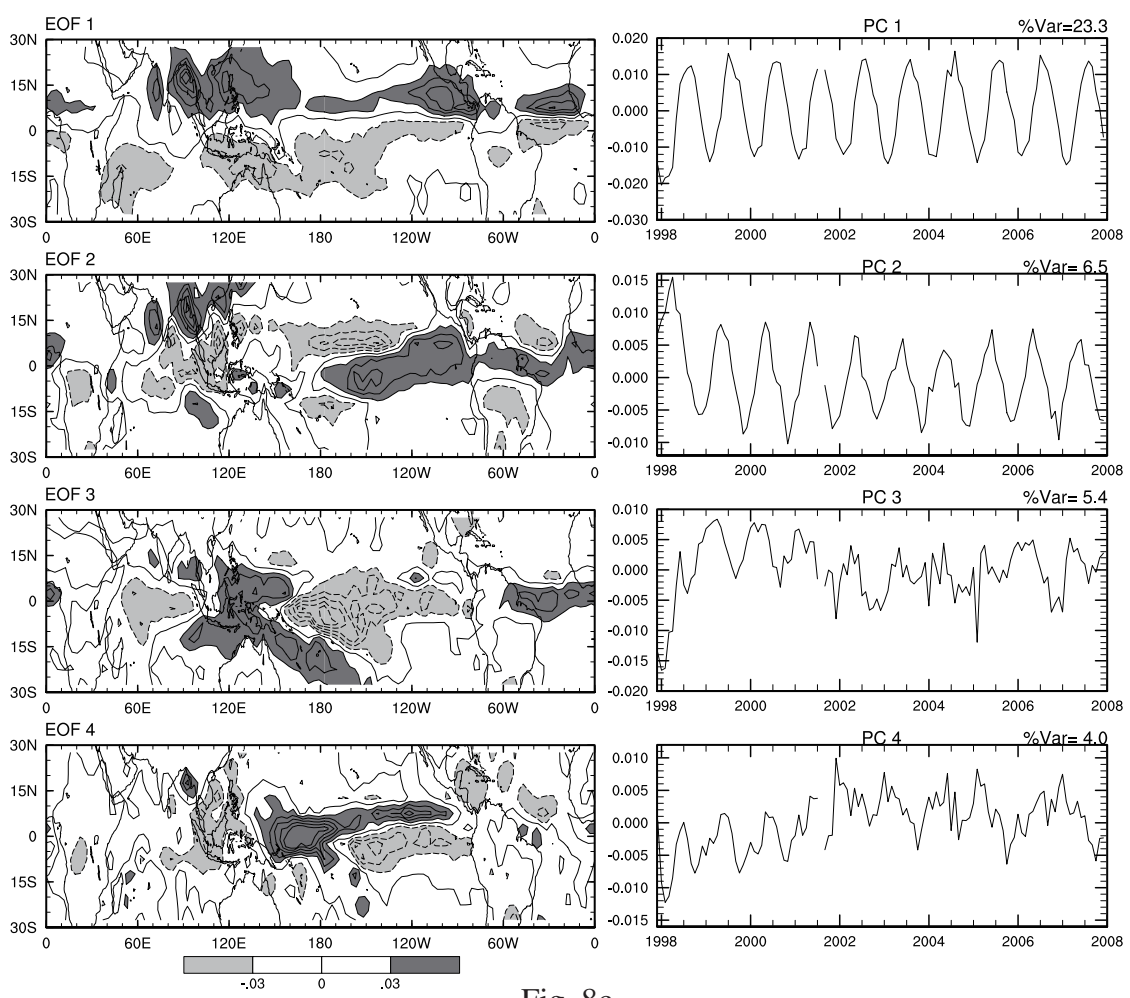

Fig. 8c 
RainH/ttIPix at $2 \mathrm{~km}(\mathrm{R}>64.8 \mathrm{~mm} / \mathrm{h})$
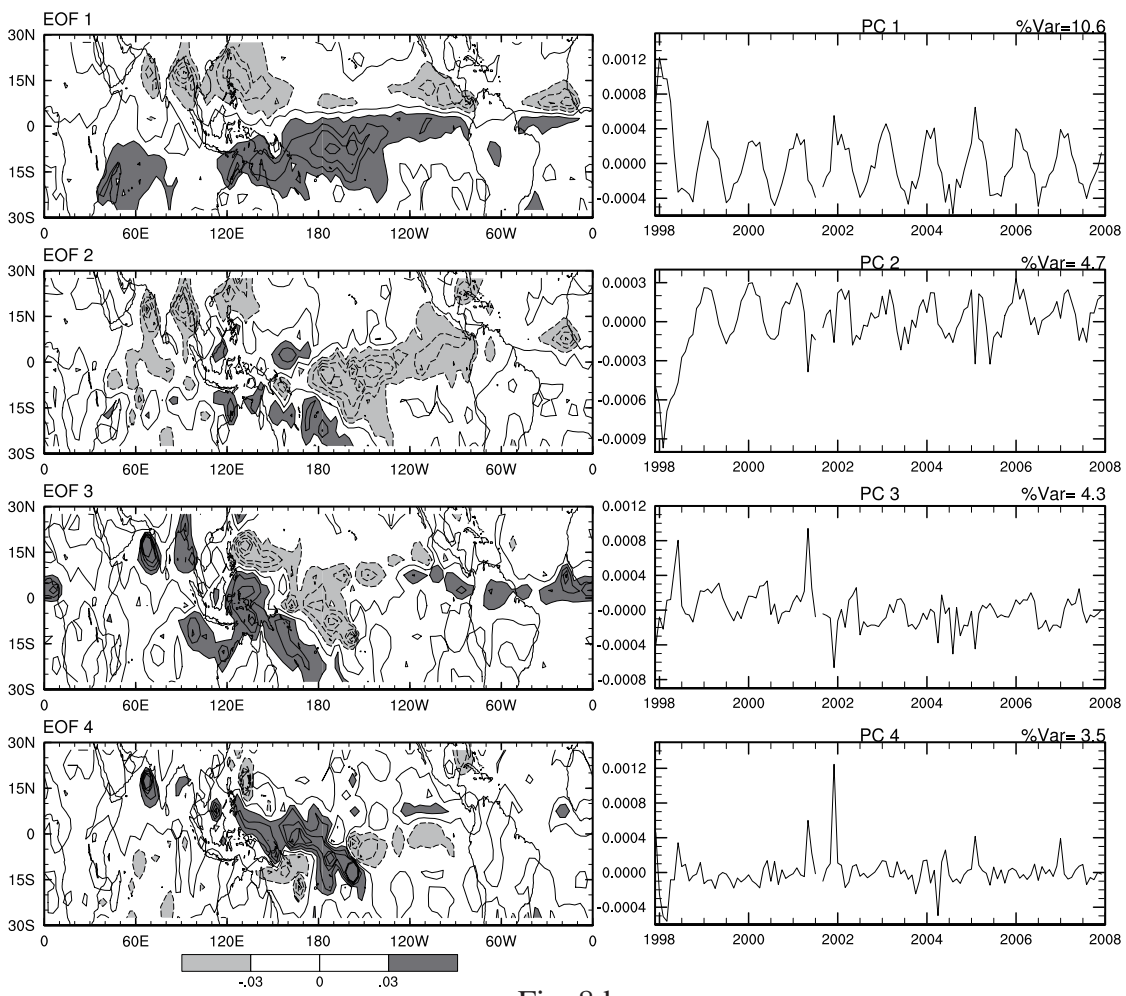

Fig. 8d

Fig. 8. Same as Fig. 7, except for the total rain rate (RainH) divided by ttlPix at $2 \mathrm{~km}$.

rates (Figs. 8b and 8c). EOF4 indicates the semiannual component.

Figure $9 \mathrm{~b}$ depicts the Lepage test for PC1-4 of OLR. HK for PC2 exhibits several peaks of 7 (above $5 \%$ significance) in early 1999, 2002, and 2006, which are related to the transition periods of the ENSO cycles. HK for PC3 also exhibits a similar tendency. HK for PC4 has a unique peak in late 2001 or early 2002. These three PCs may contribute to the zonal shift of the convective activity during the boost (Fig. 1). Interestingly, the baseline of the semiannual cycle of PC4 changed from positive before the boost to negative after the boost. Thus, in the bottom figure in Fig. 9a, the ITCZ over the central to eastern Pacific tends to become active; and the monsoon regions over India, South China, and North Australia become abruptly drier after the boost. OLR is independent of the impact of the TRMM satellite boost. Thus, the change in PC4 may come from different sources, such as the ENSO cycle. However, we do not yet know the reason at this moment.
3.4 Modulation of the annual cycle by ENSO cycle?

In the previous section, we examined the spatial and temporal patterns of the dominant modes of the rain rate variations in the TRMM PR 3A25 10-year dataset and found that sometimes two different PC time series indicate the annual cycle. Thus, in this section we further analyze the variations by plotting the scatter diagrams of two different PC time series.

Figure 10 presents the scatter diagram of $(\mathrm{PC} 1$, PC2) for the number of occurrences of convRainH less than $0.86 \mathrm{~mm} \mathrm{~h}^{-1}$, divided by ttlPix at $2 \mathrm{~km}$, as in Fig. 4a. The symbols denote the months (dot for January, circle for April, square for July, and triangle for October), and the numbers denote the years (e.g., 8 for 1998 and 7 for 2007).

Figure 10 indicates the steady annual cycles before the boost (BB) in 1998 to 2001, and after the boost $(A B)$ in the years after 2002 . That is, with respect to the gravity center, located at $(0.015,-0.01)$ of the annual cycle at $\mathrm{BB},(\mathrm{PC} 1, \mathrm{PC} 2)$ circulates clockwise in time. For $\mathrm{AB}$, the gravity center was located at 
OLR (Dec 1997 - Dec 2007)
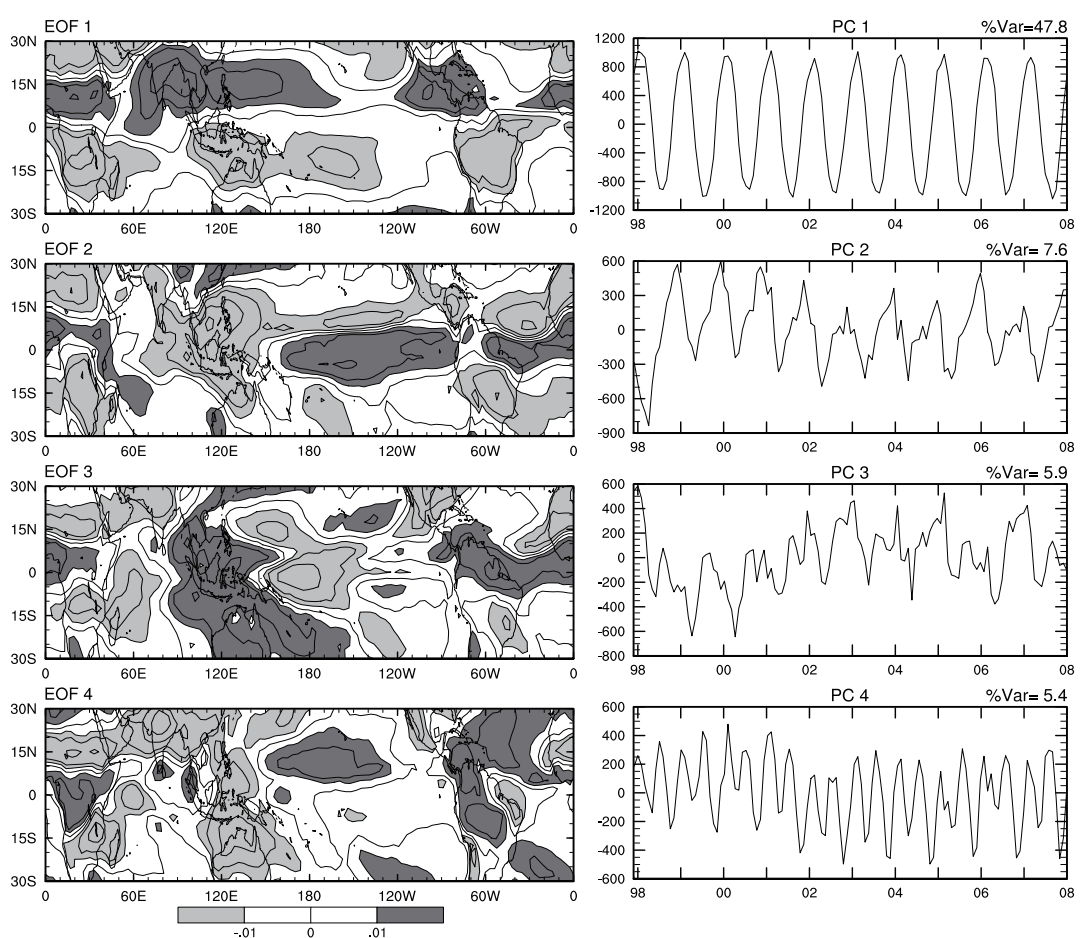

Fig. 9a
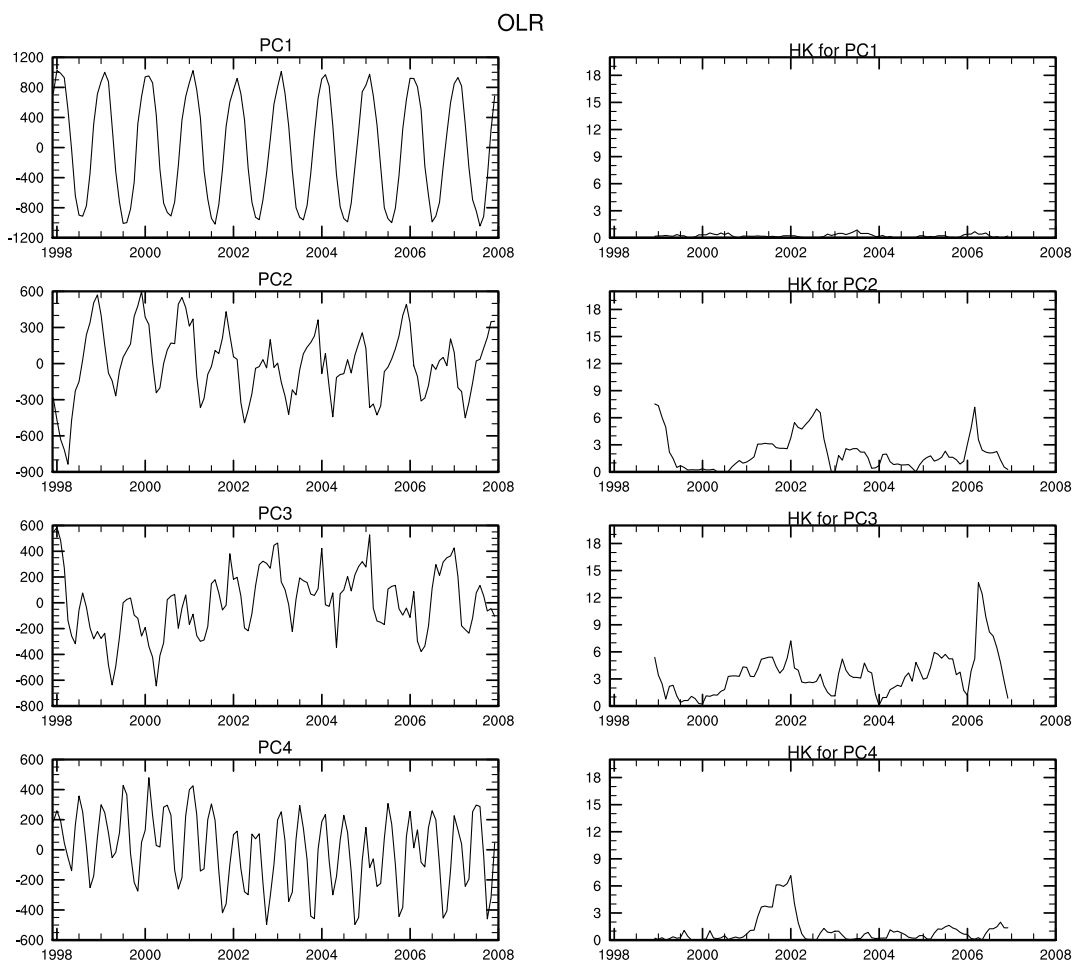

Fig. $9 b$

Fig. 9. (a) Same as Fig. 7, except for OLR. (b) Same as Fig. 6, except for OLR. 
(-0.01, 0.0025), and (PC1, PC2) also circulates clockwise with weaker amplitude. The (PC1, PC2) scatter plot illustrates the transition of the mean states before and after the boost. The gravity center of the annual cycle at $\mathrm{BB}(\mathrm{AB})$ is located where the $\mathrm{PC} 1>0$ $(<0)$, PC2 $<0(>0)$. Comparing the spatial patterns of PC1 (positive areas are dominant) and PC2 (negative areas are dominant) in Fig. $4 \mathrm{a}$, we speculate that the detection of weak rain by the PR degraded due to the boost.

We examined the corresponding variation in the global SST (Fig. 11). The first two EOFs in Fig. 11a represent the annual cycle, and the other two EOFs represent the ENSO cycle, with a strong semi-annual cycle in EOF4. EOF1 explains $79.2 \%$ of the total variance, suggesting that the major SST fluctuations can be explained by this mode. In Fig. 11b, (PC1, PC2) demonstrates clear seasonality. However, (PC3, PC4) indicates the ENSO cycle with semi-annual variability, mainly coming from PC4.

\section{Summary}

Using the 10-year TRMM PR 3A25 dataset from December 1997 to December 2007 with some statistical representations, the interannual variability of

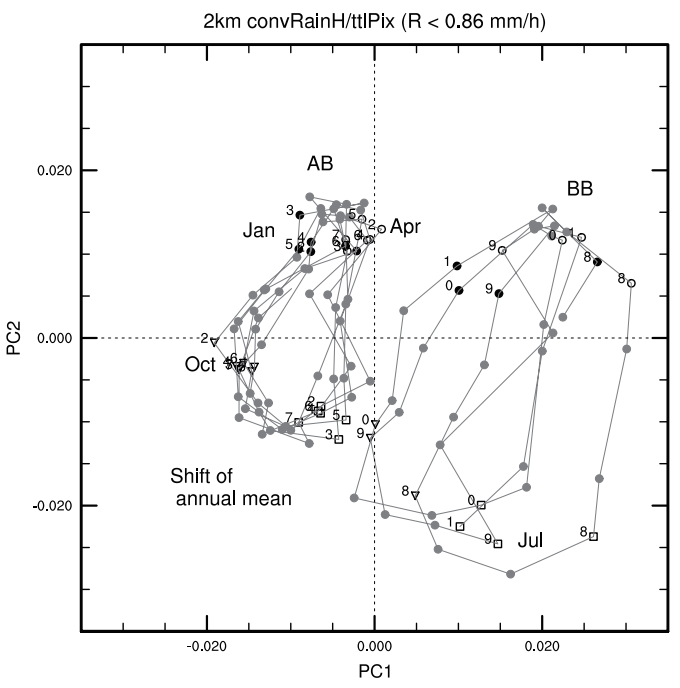

Fig. 10. Scatter diagram of (PC1, PC2) for the number of occurrences of convRainH, divided by the ttlPix, less than $0.86 \mathrm{~mm}$ $\mathrm{h}^{-1}$ at $2 \mathrm{~km}$. The symbols denote the months (dot for January, circle for April, square for July, and triangle for October), and the numbers denote the years (e.g., 8 for 1998 and 7 for 2007).
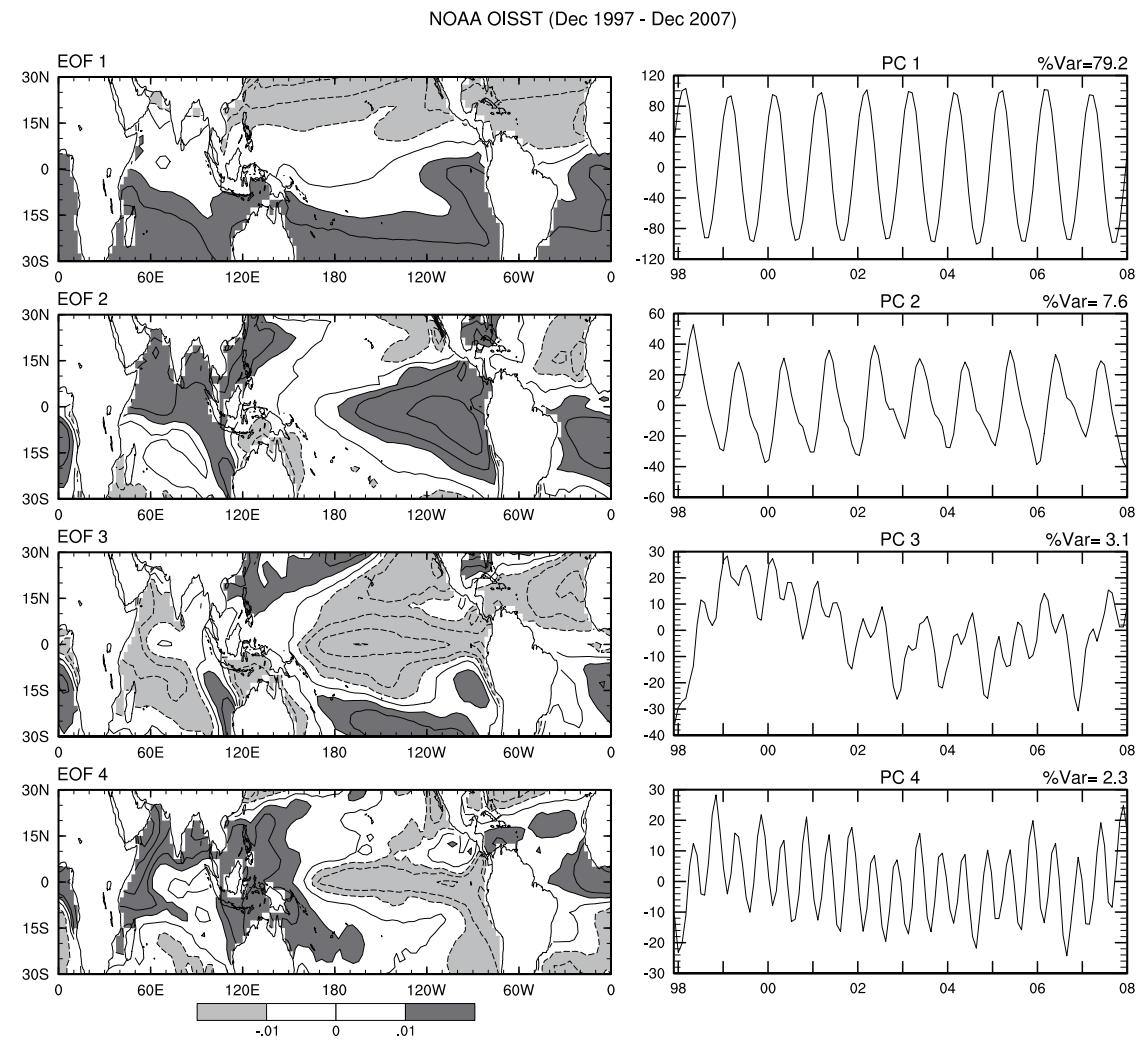

Fig. 11a 

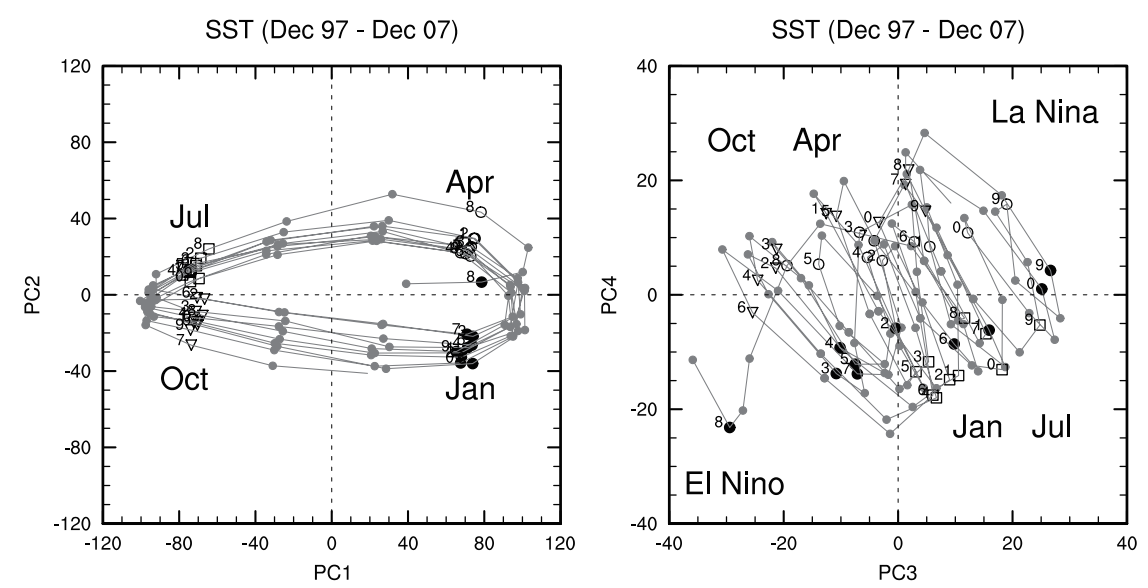

Fig. 11b

Fig. 11. (a) EOF1-4 (from top to bottom) spatial patterns and the corresponding temporal variations of PC1-4 (right) for the global tropical SST (OISST). The contour intervals are 0.01 for EOF1-4. (b) Scatter diagrams of (PC1, PC2) and (PC3, PC4) for the global tropical SST.

the rainfall characteristics in the tropics and the impact of the altitude boost of the TRMM satellite in August 2001 were examined.

The results reveal that TRMM PR 3A25 data and other TRMM datasets detect the interannual variation of rainfall over the tropics, in concert with the OLR and SST change, which is closely related to the El Niño/La Niña cycle, including pseudo-El Niño periods in 2002 and 2004.

In addition, we examined the impact of the altitude boost of the TRMM satellite from $350 \mathrm{~km}$ to $400 \mathrm{~km}$ in August 2001, and found that the boost affects the annual cycle in light rain rates (total, convective, and stratiform). A baseline shift in the annual cycle of light convRainH was observed, with more (less) frequent occurrence before (after) the boost. Amplitude changes were also observed in the annual cycle of light stratiform and total rain rate, with more (less) frequent occurrence before (after) the boost. However, for the interannual variation, we found that the coherent spatial and temporal structure of the El Niño/La Niña cycle is evident, and that the interannual variation does not exhibit any boost impact. The number of occurrences of heavy convRainH is reduced after the boost, especially over land. However, we cannot yet conclude that this reduction is related to the boost.

\section{Acknowledgments}

The authors are grateful to two anonymous reviewers for their helpful comments to improve the manuscript. This study was supported by the Japan Aerospace Exploration Agency (JAXA) under the $5^{\text {th }}$ TRMM Research Announcement on Precipitation Measuring Mission Science.

\section{References}

Ashok, K., S. K. Behera, S. A. Rao, H. Weng, and T. Yamagata, 2007: El Niño Modoki and its possible teleconnection, J. Geophys. Res., 112, C11007, doi:10.1029/2006JC003798.

DeMoss, J. D., and K. P. Bowman, 2007: Changes in TRMM rainfall due to the orbit boost estimated from buoy rain gauge data, J. Atmos. Oceanic Technol., 24, 1598-1607.

Hirakawa, K., 1974: The comparison of poers of distribution-free two-sample tests. TRU Mathematics, 10, 65-82.

Iguchi, T., T. Kozu, R. Meneghini, J. Awaka, and K. Okamoto, 2000: Rain-profiling algorithm for the TRMM Precipitation Radar, J. Appl. Meteor., 39, 2038-2052.

Lepage, Y., 1971: A combination of Wilcoxon's and Ansari-Bradley's statistics. Biometrika, 58, 213-217.

Liebmann, B., and C. A. Smith, 1996: Description of a complete (interpolated) outgoing longwave radiation dataset. Bull. Amer. Meteor. Soc., 77, 1275-1277. 
Reynolds, R. W., N. A. Rayner, T. M. Smith, D. C. Stokes, and W. Wang, 2002: An improved in situ and satellite SST analysis for climate. $J$. Climate, 15, 1609-1625.

Shimizu, S., R. Oki, T. Tagawa, T. Iguchi, and M. Hirose, 2009: Evaluation of the effect of the orbit boost of the TRMM satellite on PR rain estimates, J. Meteor. Soc. Japan, 87A, 83-92.

Shin, D.-B., and L. S. Chiu, 2008: Effects of TRMM boost on oceanic rainfall estimates based on microwave emission brightness temperature histograms (METH), J. Atmos. Oceanic Technol., 25, 1888-1893.

Takahashi, N., and T. Iguchi, 2004: Estimation and correction of beam mismatch of the Precipitation Radar after an orbit boost of the Tropical Rainfall Measuring Mission satellite. IEEE Trans. Geosci. Remote Sensing, 42, 2362-2369.

TRMM Precipitation Radar Team, 2005: Tropical Rainfall Measuring Mission (TRMM) Precipitation Radar Algorithm Instruction Manual for Version 6. Available at http://www.eorc.jaxa. jp/TRMM/documents/PR_algorithm_product_ information/pr_manual/pr_manual_v6.pdf.

Yonetani, T., 1992: Discontinuous changes of precipitation in Japan after 1900 detected by the Lepage test. J. Meteor. Soc. Japan, 70, 95-104. 